\title{
Unchecked Intermediaries:
}

\section{Price Manipulation in an Emerging Stock Market*}

\author{
Asim Ijaz Khwaja, Atif Mian
}

February 2004

\begin{abstract}
How costly is the poor governance of market intermediaries? Using unique trade level data from the stock market in Pakistan, we find that when brokers trade on their own behalf, they earn annual rates of return that are 50-90 percentage points higher than those earned by outside investors. Neither market timing nor liquidity provision by brokers can explain this profitability differential. Instead we find compelling evidence for a specific trade-based "pump and dump" price manipulation scheme: When prices are low, colluding brokers trade amongst themselves to artificially raise prices and attract positive-feedback traders. Once prices have risen, the former exit leaving the latter to suffer the ensuing price fall. Conservative estimates suggest these manipulation rents can account for almost a half of total broker earnings. These large rents may explain why market reforms are hard to implement and emerging equity markets often remain marginal with few outsiders investing and little capital raised.
\end{abstract}

\footnotetext{
${ }^{*}$ Kennedy School of Government, Harvard University; and Graduate School of Business, University of Chicago. Email: akhwaja@ksg.harvard.edu, atif@gsb.uchicago.edu. We are extremely grateful to the Securities and Exchange Commission Pakistan (SECP) for providing us the data used in this paper, and to Mr. Khalid Mirza and Mr. Haroon Sharif for clarifying questions. The results in this paper do not necessarily represent the views of the SECP. We also thank Ulf Axelson, Abhijit Banerjee, Nick Barberis, Gene Fama, Francisco Gomes, Simon Johnson, Steve Kaplan, Tobi Moskowitz, Andrei Shleifer, Jeremy Stein and seminar participants at Boston University, Chicago GSB, Harvard, LSE, MIT, LUMS, Michigan, NBER, NEUDC conference, and SECP for helpful comments and suggestions. All errors are our own.
} 
The governance of equity market intermediaries through the appropriate design and enforcement of law and regulation - particularly in emerging markets - has received increased emphasis recently (see Glaeser, Johnson, and Shleifer (2001), and La Porta, Lopez-de-Silanes, and Shleifer (2003)). There is a growing belief that emerging markets need improvements in their legal and institutional environment in order to really develop. For example, Glaeser et al argue that self-regulation by brokers in emerging economies with costly law enforcement is unlikely to be successful. However, despite such concerns, little is known about the costs of misgovernance among market intermediaries. What kind of undesirable outcomes does poor regulation and weak enforcement of law lead to? What behavior of market intermediaries should such regulation curb and what are the costs of such behavior when such legal and regulatory checks fail? This paper answers these questions by an in-depth analysis of broker behavior in an emerging stock market.

We identify brokers in the stock market who "manipulate" prices to their own advantage and at the expense of the outside investor. These brokers engage in frequent and "strange" trading patterns indicative of the anecdotally familiar "pump and dump" manipulation schemes. We show that these schemes result in substantial gains of 50 to 90 percentage points higher annual returns than the average outside investor. These large rents not only explain why many potential rational investors choose to stay out of the equity market, but also - from a political economy perspective - help understand why entrenched players so often actively resist efforts to institute reforms. If such manipulation and its magnitude is substantial, then the results of this paper would add to our understanding of why equity markets fail to develop in many poor economies. ${ }^{1}$

The manipulation activity identified in this paper is likely to be prevalent among other emerging markets. There are numerous accounts of emerging markets today which show similar concerns: Khanna, in a case study of the Indian stock market, states that "Brokers were also often accused of collaborating with company owners to rig share-prices in pump-and-dump schemes" (Khanna (1999)). Zhou and Mei (2003) argue that manipulation is rampant in many emerging markets where regulations are weak and note that China's worst stock-market crime in 2002 was a scheme by seven people accused of using brokerage accounts to manipulate company share prices.

Moreover, historical accounts of mature financial markets suggest that such manipulation is a

\footnotetext{
${ }^{1}$ In the US, an estimated 50 million individuals, or about one-fifth of the population invest in the stock market directly or indirectly through mutual funds. Over $20 \%$ of financial wealth of the average US household is held in equity and equity linked instruments. In contrast, in an emerging market like India there are believed to be no more than 3-4 million retail investors out of a population of over 1 billion, with the Reserve Bank of India estimating that less than $2 \%$ of the financial wealth of Indian households is held in equity and equity linked instruments comprised. (Source: Misra, M. (2001) "E-Broking in India - I: Adoption Patterns", White paper, Oyster Solutions.)
} 
common hurdle that young markets have to overcome. For example, the Amsterdam stock exchange in the 1700s and the New York stock exchange in the 1900s (Gordon (2000)) show a wide concern for the prevalence of price-manipulation in these markets. In fact the stated justification for the US Securities Exchange Act of 1934 was to eliminate manipulation due to "stock pools", whereby groups of traders jointly traded in a particular stock to manipulate prices.

While anecdotes abound, the lack of suitable data has made it difficult to test for these stories. This paper, to our knowledge, offers one of the first attempts at doing so by exploiting a unique trade level data set. The data set contains all daily trades of each broker in every stock trading during a two and a half year period on the Karachi Stock Exchange (KSE) - the main stock exchange in Pakistan. The micro nature of this data set not only allows us to test for a specific price manipulation mechanism, but also estimate the returns from manipulation activities in general.

Since anecdotal evidence suggests that it is the market intermediaries (brokers) who run manipulative schemes, the paper starts by differentiating between trades done by a broker on his own behalf from those done on behalf of the outside investor. Given this separation, we find that when brokers trade on their own behalf - i.e. act as "principals" - they earn at least 50 to 90 percentage points higher annual returns over, and at the expense of, outside investors.

We then test directly for some possible means of manipulation. While several mechanisms of market manipulation may exist, anecdotal evidence and cyclical trading patterns suggest a particular one: When prices are low, colluding brokers trade amongst themselves to artificially raise prices and attract naive positive-feedback traders. Once prices have risen, the former exit leaving the latter to suffer the ensuing price fall. While this mechanism is stylized, we find compelling evidence for it: First, on days when the stock-price is relatively low, principal brokers trade amongst themselves, i.e. most of the trade (both buys and sells) is done by brokers who act as principaltraders in the stock. Conversely on high price days, most trade is done by outside traders, i.e. principal-traders are out of the market. Second, trading patterns of principal brokers have strong predictive power for future returns: Periods when only principal-brokers buy and sell stocks to each other lead to positive returns. Note that such within principal-broker trading cannot, by definition, affect the profitability differential since it captures the difference in profits between principal-brokers and outside investors. Moreover there is no reason to suspect that this relationship is spurious and not causal i.e. that such trades and the future positive returns are both caused by some unobserved real factor. If this were the case one would expect the more informed/principal brokers to be either buying or selling but not doing both back and forth. Third, further evidence that this relationship 
reflects manipulation is that the price increase from back and forth principal broker trading appears "artificial": Prices collapse once the principal-brokers exit the market, i.e. the absence of principal brokers in the market predicts negative returns.

Whereas these tests provide compelling evidence for the presence of price manipulation, one may argue that the profitability differential could also arise due to reasons other than price manipulation. Two broad classes of alternative explanations are: (i) Brokers are better at market timing because of "front running" or access to private information, and (ii) Brokers are market makers, i.e. earn rents for liquidity provision services. However we show through a series of tests that these cannot be sufficient explanations for the profitability result. For example, the profitability of high-frequency "cyclical" trades is very hard to reconcile with market timing in any realistic informational environment. Similarly, inclusion of broker attributes or liquidity measures fails to account for the profitability differential.

There are natural reasons to expect that brokers have a comparative advantage in engaging in manipulation activities. They have lower transaction costs in conducting the frequent trades that may be necessary to generate momentum in a stock. They also have better real time information about the movement in prices, volumes, and traders' "expectations", and possess a natural advantage in spreading "rumors" or false information in the market - all factors crucial to the success of a manipulation strategy.

Finally, our calculations suggest that such manipulation rents are large in absolute terms. Conservative estimates reveal a $\$ 100$ million (Rs. 6 billion) a year transfer of wealth from outside investors to principal/manipulating brokers - around $10 \%$ of market capitalization. In a country with per-capita GDP at $\$ 450$ this is a significant wealth transfer. Moreover, estimates also suggest that this is significant relative to the total earnings of brokers (i.e. including estimated brokerage commissions), accounting for $44 \%$ of these earnings.

Our paper is related more broadly to the literature on "institutions" defined as the appropriate design and enforcement of law, contracts, property rights, and regulation. This literature has taken a central stage in the discussion of financial and economic development. Examples include a series of theoretical papers motivated by cross-country comparisons such as Acemoglu, Johnson, and Robinson (2001, 2002), Acemoglu and Johnson (2003), La Porta, Lopez-de-Silanes, Shleifer, and Vishny (1997, 1998, 2000, and 2002), and Shleifer and Wolfenson (2002). This theoretical interest has coincided with recent micro-empirical work that has attempted to identify channels through which weak institutions lead to corporate and financial inefficiencies (Johnson and Mitton (2003), 
Fisman (2001), Bertrand, Mehta and Mullainathan (2002), and Boone, Breach, Friedman, and Johnson (2000)). These papers identify weak shareholder protection, and "crony capitalism" as important forces contributing to the loss of minority and "unconnected" shareholder wealth.

However, while the theoretical literature emphasized the importance of institutions more broadly, the micro empirical work has primarily focused on corporate governance issues related to firm management. Thus an important complement that has remained unexplored, and that this paper tries to address, is the governance failure associated with the regulation of market intermediaries.

Our work is also related to the work of Morck, Yeung and Yu (2000) who show that stock prices in emerging markets are more "synchronous". The collusive manipulation of stock prices to attract outside investors could be one possible explanation for this finding. Similarly, the particular manipulation mechanism that we document in this paper is related to the literature in behavioral finance that examines how (irrational) positive-feedback investment strategies can lead to inefficiencies in equity markets (De Long et al, (1990b); Shleifer (2000)). In this direction, our paper provides evidence in a real world setting that outside investors indeed trade using positive-feedback investment strategies. While we do not feel we have to take a strong stance on whether such feedback trading is rational or not, the data suggests that such momentum trading by itself is not profitable.

Since there is evidence that the mature markets of today suffered similar episodes of manipulation in their early years, perhaps emerging equity markets can also overcome these difficulties by adopting similar measures that, for example, the US SEC took to curb such manipulative behavior. We briefly discuss some possible measures in the conclusion.

The rest of the paper is organized as follows: Section I provides relevant institutional background and describes the data. Section II examines broker trading behavior patterns, and Section III estimates the excess return that brokers who trade on their own behalf (principal brokers) earn compared to the average outside investor. Section IV then tests for a specific trade-based price manipulation mechanism, Section V considers alternate explanations and Section VI concludes.

\section{Institutional Background and Data}

\section{A. The Context}

Our data is from an emerging market, the Karachi Stock Exchange (KSE), the main exchange in Pakistan. In this section we highlight relevant market features arguing that while some features are different from what one may expect in mature markets, they are fairly typical of emerging markets. 


\section{Basic Features:}

The KSE was established soon after independence in 1947 and is around the median age for exchanges around the word and somewhat older than the typical stock market in developing countries (see Bhattacharya and Daouk 2002). In 2002, it had 758 stocks listed with a total market capitalization of about $\$ 10$ billion or $16 \%$ of GDP. ${ }^{2}$ Despite the small size of the market, it experiences a surprisingly high turnover (88\%). In contrast, a mature market like the NYSE is much bigger - a market cap to GDP ratio of $92 \%$ - and has not as high a turnover (65\%). However, Figure 1 establishes that this feature of the KSE - a shallow market with high turnover - is quite common amongst emerging stock markets: It plots the size (market-cap/GDP) and turnover (dollar-volume/marketcap) of stock markets around the world against the logarithm of GDP per capita and establishes that the KSE is by no means an outlier in having a small size yet high turnover. Moreover, the regression lines through the two figures suggest that while market size is highly correlated with richer economies (Rsq is 32\%), market turnover has no significant relationship with per-capita wealth (Rsq is $0.3 \%$ ). Both the shallowness of the market and the high level of turnover in emerging markets are of particular interest as the former makes it more amenable to, and the latter more indicative of the problems arising from poor information, insider trading, liquidity, and manipulation.

Another aspect common to emerging markets is the limited role they play in raising capital: In the KSE there were only two new listings in the market in 2001 raising $\$ 33$ million and 18 delistings that year. Other emerging markets fare similarly with the majority seeing only a handful of new listings and little capital raised - In 2001, 28 out of 49 emerging markets had 2 or less new listings in the year with 15 of these markets raising less than a million dollars. In contrast, of the 50 markets classified by the World Federation of Exchanges as non-emerging, only 7 had two or less new listings in 2001 and only 8 raised less than a million dollars in new capital (Source: World Federation of Exchanges 2003).

Figure 2 shows that in addition to the high turnover, the KSE has high price volatility. It plots the KSE100 price index ${ }^{3}$ over the five year period from 1997 to 2002 including the 32 months covered by our data set. During this period, the stock market experienced both large overall busts and booms but also significant fluctuations over shorter time intervals. The standard deviation of monthly stock returns for the KSE 100 index during this period was 11.2 (as compared to 5.1 for the Dow-Jones index during the same period). These movements are all the more surprising

\footnotetext{
${ }^{2}$ The KSE captures $74 \%$ of the overall trading volume in Pakistan. There are two smaller stock exchanges covering the remaining 26\%: The Lahore stock exchange (22\%), and the Islamabad stock exchange $(4 \%)$.

${ }^{3} \mathrm{~A}$ weighted price index of the top 100 firms listed on the stock market.
} 
given the low level of real investment activity in the stock market. Again the high volatility is not atypical of emerging markets (see Bekaert and Harvey (1997)).

Finally, Figure 3 highlights another aspect of the KSE that is common in emerging markets - a skewed size-distribution of stocks traded. Of the 758 firms listed on the stock exchange, only 648 were actively traded during our sample period and of these, the top 25 stocks accounted for $75 \%$ of the overall market capitalization, and $85 \%$ of the overall turnover. In fact, such skewness is common even amongst smaller European markets (exchanges in Hungary, Portugal, Ireland, Iceland etc.) with the 5 most traded shares comprising more than $70 \%$ of turnover - the corresponding share of the top 5 is $68 \%$ share for the KSE. ${ }^{4}$ We are cognizant of the skewed size distribution of the stocks in our data set. As the empirical section will make clear, we adopt a number of procedures such as stock fixed effects, size-weighted regressions, and restricting sample to only the top decile of stocks, to ensure none of our results are driven by the skewness of the data.

In comparison to stock size, the distribution of broker size and coverage for the universe of brokers (147) trading on the KSE is not as skewed. Figures 4a-b plot the density functions (PDF) of broker size (total trading value of a broker) and coverage (number of stocks a broker trades in) during our trading period.

To summarize, a small and shallow equity market with high turnover, little real investment activity, high price volatility and skewed size distribution are all features of KSE that are very typical of emerging market stock markets around the world.

\section{Regulatory environment:}

Before describing the role of brokers in the governance of the exchange, it is worth outlining the relevant regulatory environment in the country. In particular, it is useful to examine how Pakistan fares in terms of its regulatory laws pertaining to the stock market both in absolute terms and relative to other countries. We do so by drawing on a detailed categorization of securities laws conducted by La Porta et. al.(2003) with the help of local attorneys in a sample of 49 countries with the largest stock market capitalization in 1993. They construct two broad measures to capture "private" and public enforcement implied by the securities laws. The former measure captures the extent to which securities laws reduce the costs of private contracting by standardizing securities contracts (by mandating disclosure requirements) and clarifying liability rules for inaccurate/incomplete disclosure. The latter measure, public enforcement, captures the extent to

\footnotetext{
${ }^{4}$ In contrast for the London stock exchange the comparable percentage was around 24 in 2002 . (Source: The Federation of European Securities Exchanges).
} 
which a public enforcer (the Securities and Exchange Commission - SECP - in the case of Pakistan) regulates the market as determined by the basic attributes (independence etc.) and investigative powers of the regulator, and the ability to impose non-criminal and criminal sanctions for violations of security law.

While Pakistan is near the mean value of the private enforcement measure in the sample of 49 countries, it is the third worst in these measures when looking only at the 18 common law countries to which it belongs. What is perhaps even more telling of weak investor protection in Pakistan is that in public enforcement, while Pakistan ranks very high in terms of the supervisor's attributes (independence etc.) and investigative powers, it does very poorly in terms of both non-criminal and criminal sanctions that the supervisory agency can impose for violations of securities laws. Thus it is not surprising that to date there has hardly been any case where a broker was prosecuted for improper activity. ${ }^{5}$

\section{Broker Influence:}

While the KSE does receive some oversight from the Securities and Exchange Commission of Pakistan (SECP) it is predominantly broker-managed, i.e. a majority of the exchange's board of directors including the chairman are brokers. ${ }^{6}$ Moreover trading on the stock exchange can only be done through one of the 147 licensed brokers, and entry into the brokerage system is restricted. A new broker can only enter through the sale of an existing brokerage license. ${ }^{7}$ These features are important from a governance perspective. If brokers are earning persistent "rents" from suspect activities in the market, and there are breakdowns in Coasian bargaining (e.g. future gains from reforms cannot be guaranteed to the rent-seeking brokers), then governance of the market will be kept intentionally weak.

All these features and numerous anecdotes allude to a significant amount of broker control of the market. We highlight this aspect since, in focusing on potential market manipulation, most

\footnotetext{
${ }^{5}$ We are aware of only one instance where a legal case was brought before a broker for any reason and "section 17 " of the regulatory code applied (a claim made on the broker's assets). What is interesting is that this case arose not due to regulatory vigilance but because of what appears to have been a conflict between brokers. This resulted in a couple of brokers crossing their exposure limits and defaulting (they were unable to pay the difference between their position and actual exposure limit).

To quote from the Business Recorder, one of the leading Financial papers in Pakistan (June 2nd, 2000) regarding this incident: "It is not the issue of just payment, it is a war between the Karachi and Lahore based major groups who are struggling for their survival in the market, said an insider on condition of anonymity."

${ }^{6}$ This is not atypical. For example, in Turkey of the five members of the board of directors, four are brokers, and one is appointed by the government.

${ }^{7}$ In practice such sales are rare both because of the high price of brokerage seats - e.g. in 2000 the license of a defaulting broker was sold for US\$0.5 million (per capita GDP is $\$ 450$ ) - and the fact that these sales typically take place in thin markets with access limited to insiders.
} 
anecdotal evidence suggests a closer examination of broker trading patterns. Specifically, interviews of market participants in Pakistan suggest that a substantial number of brokers act as principals (trade for themselves and/or a few investors) rather than intermediaries and such brokers contribute to potentially undesirable activity in the market. To quote from an SECP report:

"Brokers mostly act as principals and not as intermediaries .....(this has led to) ..extremely high turnover ... extensive speculation ... (and) ...very little genuine investment activity, (with) hardly any capital raised .....To restore investor confidence: (i) stock exchange management should be freed from broker influence .... and (ii) government must support and visibly seen to be supporting the SECP's reform agenda." - SECP report to the President - July 2001.

Moreover, the presence or at least allegations of market manipulation, particularly in the form of price-manipulation, is common knowledge among the primary market participants, as is the belief that it is generally these principal brokers themselves (or their close associates) who are involved in manipulative activities. A common form such manipulation takes is brokers colluding to artificially raise prices in the hope of attracting and eventually making money at the expense of naive outside investors. Special terms, such as bhatta, have been coined in Urdu, the local language, to define such behavior. Similar "pump-and-dump" schemes are also believed to exist in other emerging markets (see Khanna (1999) for the Bombay stock Exchange in India) and were quite prevalent in the early stages for developed markets as well. Gordon's (2000) account of the New York Stock Exchange in the 1900s is quite revealing and could just as well be an accurate description of the KSE today (relevant parts emphasized):

" By 1920 the phenomenal growth of the American economy ... had made the New York Stock Exchange the largest and most powerful institution of its kind in the world. But ... it was a private club, operating for the benefit of its members, the seat holders, and not the investing public... The floor traders ... traded only for their own accounts. They had two great advantages over the ordinary investors and speculators who increasingly haunted the board rooms of brokerage offices as the decade progressed. Because they had access to the floor itself, they had the latest possible information on how the market, and individual stocks, were moving and could execute trades with lightning speed. And because they paid no brokerage commissions, they could move in and out of stocks and bonds as often as they liked, taking advantage of small swings in price much as the new "day traders" can do today on the Internet. Unlike today's day traders, however (at least so far), they could also conspire with each other and with specialists to manipulating the market to their advantage ... Pools, wherein several 
speculators banded together to move a stock up and down, were common. Although so-called wash sales (where brokers reported sales that had not, in fact, taken place) were prohibited, the pools carefully timed sales within the group, called matched orders. These sales could be used to produce a pattern on the ticker (called painting the tape) that would induce outside speculators to buy or sell as the pool wished. When their object had been achieved, they could close out the pool at a tidy profit, leaving the outside speculators holding the bag ... It was, at least for the quick-witted and financially courageous, a license to steal. Whom they were stealing from in general, of course, was the investing public at large but they sometimes stole even from less favored members of the club". (pg.213)

Recent reforms by the government regulatory authority, the SECP, such as appointing independent (non-broker) members in the board of directors have been targeted at weakening broker influence, although to date these reforms have had limited success. The issue of broker control has been one that has historically plagued markets during their early stages and appears present in emerging markets today. ${ }^{8}$

\section{B. Data}

One of the unique features of this study is the level of detail available in the data: The data set consists of the entire trading history for KSE over a 32 month period (21 December 1998 to 31 August 2001). What is unique about this data and allows us to look at broker-level trading behavior, is that it contains the daily trades of each broker for every stock over the 32 month period. We are not aware of any other work that is able to analyze trading for the entire universe of trades in a market and at the level of the broker. During the 32 month period, there were a total of 147 licensed brokers and 648 stocks trading on KSE. The data set thus contains almost 2.2 million observations at the broker-stock-date level.

Moreover, since trading on KSE during our sample period was all computerized (brokers submit their orders electronically to an automated system that then matches the orders for execution) and the dataset was extracted directly from this system, the quality of the information is very reliable. Specifically, since trading on the KSE can only be performed by a licensed stock broker, each trade order (buy or sell) is recorded under a particular broker name. For each broker-stock-date, our data set contains: (i) the total number of shares bought or sold through the broker during the day, and (ii) the closing, highest, and lowest prices for each stock traded during the day.

\footnotetext{
${ }^{8}$ While the NYSE has tried to minimize the conflict of interest likely to exist in a self-regulatory institution by having equal representation of industry (i.e. brokers) and non-industry members (representing the investing public) on its board of directors, the potential for conflict still remains. This is apparent in the recent debate and concerns regarding governance issues in the NYSE (http://www.nyse.com/home.html).
} 
However, there are also some limitations of the data. First, trades for a given broker in a given stock are aggregated at the day level. Therefore, our analysis is conducted using a day as the primitive unit of time, and the average price during the day as a proxy for the trade price. ${ }^{9}$ While this does preclude intra-day analysis, we do not feel that this exclusion changes the quality of our results. For example, given that we find brokers make profits through manipulation in inter-day trading, not accounting for the intra-day profits of these brokers is only likely to make our estimates to be an underestimate of the true effect. Second, we do not have information at the investor level i.e. while we can identify the broker, we do not know the investor he is trading on behalf of. However, as we will show, we can construct proxies for whether the broker is trading on his own behalf or on behalf of outsiders. Additionally, since only completed trades are recorded, we do not have information on unfulfilled bids.

\section{Broker Trading Patterns: Is there anything unusual?}

The substantial broker influence suggested in the previous section and the concern by the market regulatory body that "Brokers mostly act as principals and not as intermediaries" suggests that we should start by examining trading patterns to see if this concern is true. More generally, we want to identify any "unusual" trading patterns and a suitable "normality" benchmark, given the context, is whether a broker is acting as an intermediary for different outside investors. While we do not have data on whom a broker is transacting on behalf of, we use indirect means to identify such unusual (i.e. non-intermediary) behavior. We should emphasize that we do not read too much in the label "unusual" for now and remain agnostic about such patterns since there may be perfectly legitimate reasons why a broker would only execute trades on his own behalf during the day.

Table 1 provides an extract of the data to illustrate representative trading patterns. The two columns in Table 1 list the aggregate buys and sells on a given day of two different brokers in the same stock. For the broker in column (1) (Broker A) we list 20 consecutive aggregate day trades. Recall that we do not observe each individual trade done by the broker but the sum of all his buys (and sells) in a given stock on that day. Henceforth, we refer to such aggregate buys and sells simply as "trades", it being understood that we are always referring to the aggregate trades during the day and not a particular transaction. For the broker in column (2) (Broker B) we give three separate periods of consecutive trades to illustrate different trading patterns this broker displays.

\footnotetext{
${ }^{9}$ Average price is constructed using an average of the highest and lowest prices during the day. Our results are unchanged whether we use the highest, lowest, or closing price as a proxy for trade price instead.
} 
Even a cursory examination of the trading patterns between the two brokers in Table 1 reveals an interesting difference: Broker A both buys and sells stock on a given day (and usually in different amounts). This is not surprising. If a broker is intermediating on behalf of several independent investors, he would be both buying and selling the stock on the same day since it is unlikely (though possible) that different investors would all want to collectively buy (or collectively sell) on a given day.

Broker B however behaves very differently from Broker A. On any given day he only either buys or sells (i.e. does not do both) or buys and sells exactly the same amount. As a first pass, we consider Broker B's trades as unusual in the sense that they are likely to reflect trading by a single investor or a group of investors who are in perfect agreement - we will refer to such trades as "principal trades". While a few such trades are not surprising, a long sequence of such principal trades makes it far more likely that the broker is not really intermediating for different investors, but is acting like a "principal" investor (a single or, what will be observationally equivalent for us, a perfectly colluded set of investors). Note that in addition to either only buying or selling, Broker B also trades "cyclically" during period 2 i.e. he only buys (or sells) on a given day and then exactly reverses this trade the next time he trades (or reverses the trade within the same day). Such cyclical patterns of trades is also less likely for a broker who is intermediating on behalf of many independent investors.

While Table 1 is useful in that it illustrates unusual trades, it does not provide any sense of how prevalent such trades are. In order to do so we categorize Broker B's unusual trades into three types:

(i) Trades where a broker only buys or sells on a given day, and exactly reverses this trade the next day he trades OR trades where the broker buys and sells exactly the same number of shares on a single day: We will refer to such trades as "principal cycles" (Broker B's trades in period 2). (ii) Trades ("principal buys") where a broker only buys the stock during the day and does not reverse this position the next day. For example, Broker B's trades in period 1.

(iii) Trades ("principal sales") where a broker only sells the stock during the day and does not reverse this position the next day. For example, Broker B's trades in period 3.

In contrast, all but one of Broker A's trades involve the broker both buying and selling a different number of shares for a given stock and day. We refer to these trades as "intermediary trades" since, as we argue in more detail below, we believe that such trades are more likely if a broker is intermediating on behalf of different investors during the day. 
Based on this categorization, Table 2 establishes that the trades by Broker B are prevalent in the full sample: Column (1) shows that $60 \%$ of all trades are one of the three types seen for Broker B (around 20\% each). Columns (2)-(3) provide the same relative frequencies but weighted by the amount traded - in other words they provide the probability that a randomly selected single-stock trade belongs to one of the four types. Given the skewed distribution of stock turnover (Figure 3), we present the results separately for the top 10 stocks (Column (3)), and the remaining stocks (Column (2)). Column (2) shows that while most stocks are traded through intermediary trading, even by this criteria there is a significant share of trades of the type carried out by Broker B. Not surprisingly, the majority of activity in the top 10 stocks is intermediary trades. Since the total number of brokers is fixed, the larger a stock is in terms of its turnover, the more likely is a broker to intermediate this stock over and above his own personal trading. Consequently for larger stocks, more trades appear like intermediary trades. In any case, it seems reasonable to conclude that the unusual trades we identified in Table 1 (Broker B) are not just chance occurrences but are frequent both in terms of incidence and volume.

Table 2 also presents a first pass at when these four types of trades are more likely to take place. Column (4) shows that principal buys occur at the lowest normalized (by sample period average) stock prices and intermediary trades at the highest. Moreover, since principal sales occur at higher prices than principal buys, this suggests that a broker who only engages in such principal trades will, all else being equal, earn positive profits. Column (5) shows that both intermediary trades and principal cycles are associated with relatively high turnover (turnover on a day is normalized by its average over the sample period for that stock). However, both the principal buys and principal sales occur on relatively low-turnover days suggesting a potential liquidity provision role of such trades.

Thus our examination does reveal somewhat unusual broker trading behavior that is also systematically associated with stock prices and trading volumes. However, in mapping such unusual trades to brokers we need to understand who executes them. Specifically, do such unusual trades occur uniformly across all brokers or do some brokers (like Broker B) systematically engage in such trades in a given stock. More importantly, if such behavior is systematic for a given broker, does it impact the overall trading profits generated by the broker? 


\section{Trading Profitability}

The description of the market and environment in Section I suggests that brokers, especially those who trade on their own behalf, may be trading strategically and in a potentially manipulative manner. The previous section offered an indirect way of identifying such "principal brokers". In this section, we will first formalize this identification strategy and then check whether these principal brokers systematically generate greater trading profits.

\section{"Intermediary" vs. "Principal" Brokers:}

We first describe the construction of our main variable of interest in this paper, PRIN. It measures the extent to which a broker in a given stock is trading on his own behalf (i.e. acts as a principal) as opposed to trading on behalf of others.

Suppose that the three types of "principal" trades identified in Table 1 signify that the broker is trading on his own behalf that day. The assumption that a "principal" trade always reflects a broker trading on his own behalf does not need to be true all the time. All that we need is that "principal" trading is correlated with a broker trading on his own behalf. Then for each broker in a given stock, we can compute the probability that a broker will do a "principal" trade. This is our measure PRIN. More precisely,

$$
P R I N_{S B}=\frac{\text { Number of times broker } B \text { trades as a "principal" in stock } S}{\text { Total number of times } B \text { trades in stock } S}
$$

The subscript $S B$ is added to reiterate that $P R I N$ is constructed separately for each broker $B$ in every stock $S$. Thus in our example of Table 1, Broker A has a PRIN value of 0.05 for the 20 trades shown, ${ }^{10}$ and Broker $\mathrm{B}$, a $P R I N$ value of 1.

PRIN serves as a proxy for the extent to which a broker is trading on his own behalf for a given stock ( interpreted more broadly as the broker trading on behalf of one investor or a perfectly colluded set of investors). It is important to emphasize here that PRIN only serves to order brokers by "principalness" within the same stock. For example, a high PRIN value in stock $i$ cannot be compared to a low $P R I N$ value in stock $j$. The reason is that the level of PRIN is affected not only by the the "principalness" of a broker, but also by stock specific attributes particularly stock liquidity and turnover. In particular, if there is more frequent and heavier trading in stock $j$, then on average all brokers in stock $j$ will have a lower PRIN.

\footnotetext{
${ }^{10}$ The third trade of broker A (15,000 buys and sells) will count as a principal cycle.
} 
The measure in (1) therefore must be "demeaned" at the stock level before it can be used in the analysis. We can use two approaches to de-mean PRIN. The first uses PRIN with stock level fixed effects, to construct a cardinal ranking of brokers within each stock. The second approach uses PRIN to construct an ordinal ranking of brokers within each stock separately. This ranking, $P R I N^{\text {ord }}$, reports the percentile of the broker in the PRIN distribution for a given stock. While we will primarily use the first, our results are robust to the second.

Using either the cardinal or ordinal version of PRIN, brokers with low values of PRIN can be thought of as "intermediaries", and those with high values of PRIN, as "principals". Thus in our example in Table 1, Broker A would be considered an intermediary and Broker B, a principal. Alternately, PRIN can be regarded as a proxy for the probability that a broker is a principal.

The computation of PRIN collapses our data to the stock-broker level. In other words the time component in our stock-broker-day data is collapsed in order to construct the PRIN measure. For example suppose that Brokers A and B in Table 1 trade in a total of 300 and 400 stocks respectively. After collapsing the time dimension in order to construct the PRIN measure for each broker-stock pair we will be left with 300 observations (i.e. PRIN values) for broker A and 400 observations for Broker B. Applying this construction to all brokers in the actual data we end up with 46,325 stock-broker level observations (note that as Figure 4b shows not every broker trades in each stock).

Given a measure of how much a broker trades on his own behalf, the question to answer is: do brokers who are more likely to trade on their own behalf (i.e. have a higher PRIN for a given stock), make more money? In order to answer this question, we first construct a measure of trading profits of a broker in a given stock.

\section{The Profitability Measure:}

We construct an annualized nominal rate of return $(A R R)$ for each stock-broker using his entire trading history (i.e. buy and sell orders for the stock) over our sample period. The $A R R$ measure captures the trading profits a stock-broker generates per unit of capital invested. Thus a $50 \% A R R$ implies that the stock-broker is able to earn $R s 50$ in a year on an average capital investment of Rs 100 during the year.

In constructing $A R R$ we need to be aware of potential issues that may arise from limitations of our data. While our results are robust to these concerns, it is nevertheless worth mentioning them. First, we value the sale or purchase price on a given day at the average price of the stock 
that day since we do not have data on the price each specific trade was conducted at. ${ }^{11}$ Second, a problem in calculating $A R R$ over the sample period is that the trading history may not net out to zero. In particular, if a broker is a net accumulator or a net decumulator of a stock over our sample period, we need to come up with a strategy to value his end of sample net holdings. We take the simple approach of valuing his end of sample net holdings using the end of sample stock price. To put it differently, we "force" the stock-broker to liquidate any net positions at the end of sample price. However, our results are robust to more complicated solutions to this problem such as "netting out" end of period holdings i.e. impose a "zero-profit" condition on end of period net holdings rather than forcing liquidation. The appendix describes the $A R R$ construction and these issues in more detail.

For the sake of clarity, we should emphasize what $A R R$ measures and what it does not capture. First by construction, $A R R$ only measures inter-day profitability due to trading. It does not include any profits (or losses) that a broker may have accumulated due to intra-day trading. Second, ARR does not include trading commissions or bid-ask spreads earned by brokers. Third, ARR only computes profitability of a broker during our sample period, and as such is unaffected by the value of a broker's inventory going into our sample period.

Finally, it should be pointed out that given some outliers in the ARR after construction, we winsorize the data at $1 \% .^{12}$

\section{A. Primary Regression:}

We can now compare trading profits principal brokers earn relative to intermediary brokers. In terms of interpreting any profitability differences it is important to realize that as we are only looking at trading profits and not brokerage commissions. Thus the profitability comparison is between principal brokers (i.e. the single/perfectly colluded investors behind them) and the outside investors who trade through intermediary brokers. For the purposes of this paper, it is precisely this comparison that we are interested in making, since we care less about what brokers earn, but rather

\footnotetext{
${ }^{11}$ Average price is the average of the high and low price for the stock during the day. Our results are robust to using high or low price instead. Also note that we do not necesarily have to assume frictionless short selling to legitimately do this. An alternative explanation of a within-sample "short sale" is that the stock-broker is simply borrowing the stock from his net inventory of the stock prior to the beginning of our sample period. It is certainly safe to assume that such "borrowing" is frictionless. Also note that there is no formal derivatives market in KSE during our sample period. There is a forward trading facility or "badla" market for brokers which is explained in detail in section V, subsection B-2."

${ }^{12}$ The results remain the same whether we winzorize the data - the top and bottom $1 \%$ outliers in $A R R$ are "assigned" the value at the $99^{t h}$ and $1^{\text {st }}$ percentile respectively - or simply exclude the outlyers from the regressions. We prefer the former as is standard practice and more consistent with the data.
} 
what their trading strategies, and hence the investors behind them, earn. However, for simplicity, we will treat a principal broker's trading profits as the broker's own earnings (this is true if the broker is trading on his own behalf since he won't earn any commission). While we could interpret these trading profits as the earnings of the single or perfectly colluded set of investors behind this principal broker, as will be clear later on, for our purposes the two are equivalent. ${ }^{13}$

Before turning to regression analysis, it is worth "eye balling" the aggregate data to detect any patterns in profitability. To do so, we first categorize PRIN $N^{\text {ord }}$, the ordinal percentile ranking of PRIN within each stock, into 10 different bins with each bin representing a decile. Then for each bin, we compute the aggregate profitability of stock-brokers in that bin by dividing their total level profits by the total average capital used by each of the stock-brokers. In other words, we construct a single $A R R$ number for each bin (ARR-cat) rather than taking the average of the $A R R$ s for all the stock-brokers in the bin. We can then compare the profitability across the $10 P R I N^{\text {ord }}$ deciles (Figure 5).

The figure shows a striking result: Not only do brokers in the top PRIN ${ }^{\text {ord }}$ decile in each stock, earn a high rate of return of over $20 \%$, they do so at the expense of the low PRIN ${ }^{\text {ord }}$ deciles. i.e. brokers who trade as principals earn significantly higher returns over, and at the expense of, outside investors who trade through intermediary brokers.

While the figure suggests that this profitability difference is significant, we now turn to a regression framework to show this formally. We estimate:

$$
A R R_{S B}=\alpha+\beta \cdot P R I N_{S B}+\underline{\gamma} \cdot \underline{S}+\varepsilon_{S B}
$$

$\underline{S}$ refers to stock level fixed effects. $\beta$ in (2) captures the superior returns that "principal" brokers $(P R I N=1)$ receive over "intermediary" brokers (outside investors) with the lowest possible value of $\operatorname{PRIN}(0)$. The fixed effects $\underline{S}$ ensure that we only compare brokers within the same stock. Columns (1) and (2) in Table 3 (Panel A) report the results of this regression: Column (1) first takes a slightly naive but simpler approach in that it weighs each observation equally. However, the problem with doing so is that, given the construction of the PRIN measure, there are several small stock-brokers who appear with a large $P R I N$ value simply because they trade infrequently

\footnotetext{
${ }^{13}$ Clearly the interpretation of our results and policy implications vary slightly if it is the principal broker who is directly profiting as opposed to a single or perfectly coluuded set of investors behind him. However, given our data, we cannot make this distinction. Moreover, we feel that the point this paper is making - that unchecked and suspect (i.e. manipulative) trading by certain individuals systematically earns money off outsiders - is well made under either interpretation.
} 
in the firm. Column (2) provides a more meaningful estimate that gets at the economic significance of the effect by weighing each observation by the average capital investments by the broker in the stock during the data period. Nevertheless, both versions show a large effect: Brokers who trade primarily as principals (whether cyclically or not) earn an annual rate of return that is 35-48\% higher than those who trade as intermediaries. The effect is highly significant We only report results with stock fixed effects, but the results are similar without stock fixed effects.

Note that our interpretation of this effect is that it is the profitability differential between trades conducted by a broker for himself or a few perfectly colluding investors (a principal trade) versus trades conducted by other brokers on behalf of independent outsiders (intermediary trades). To the extent that some of the trades conducted within a day by an intermediary broker may also be on his own behalf rather than for outsiders, our estimate of the profitability differential is in fact an underestimate of the true effect (since the PRIN measure incorrectly groups these as intermediary trades as well).

Before seeking explanations for this "principal-trading" effect, we first perform a series of robustness checks. Since the weighting strategy correctly puts less emphasis on stock-brokers who had high PRIN values only because they trade infrequently, we stick to weighted regressions. As will be apparent in the next section, it is unlikely that such inactive brokers give rise to the principal-trading effect: While they are trading for themselves, their motivations for doing so may be entirely different from the strategic motivations of the active principal-brokers.

\section{B. Non-linear Specification:}

We have assumed a linear specification in our regressions. However, since the distribution of $P R I N$ has greater mass at a PRIN value of 1, we would like to ensure that our results aren't driven by imposing a linear form. We therefore re-run (2) with an additional dummy for stock-brokers whose $P R I N$ is 1 . Column (3) shows that there is no non-linearity when PRIN is 1 , and the linear effect of PRIN for PRIN less than 1 remains at $48 \%$.

\section{Allowing for Margin Trading:}

Our definition of profitability, $A R R$, takes a restrictive and conservative view as it does not allow brokers to trade on the margin. Specifically, in computing the capital required by the broker when trading in a particular stock, we impose a $100 \%$ margin requirement i.e. at any point in time the broker has to have as much capital as his net position on that day (less any profits he may have 
earned in the trading we observe before). Thus if on the first day we observe him, a broker has a net buy of stock valued at Rs. 100, we assume that he is required to hold capital worth Rs. $100 .{ }^{14}$ However, in reality the KSE and other stock markets, do allow brokers to trade on margin. While brokers on the KSE are even able to trade with a 10\% margin, we use two conservative measures allowing for $40 \%$ and $20 \%$ margin requirements respectively. Columns (4) and (5) show the results from allowing for margin trading and as expected, the principal-trading effect increases to $72 \%$ and $89 \%$ respectively. While we believe that these estimates are more likely to reflect the rates of returns that principal-brokers are earning, we will continue with the more conservative approach of adopting a $100 \%$ margin requirement in the remaining results.

\section{Ordinal and Discrete PRIN measure:}

One of the concerns may be that we are taking the continuous PRIN measure too literally and imposing cardinality may be driving our results. Column (6) addresses this concern by reestimating our primary regression using the ordinal measure of $P R I N, P R I N^{\text {ord }}$, to construct a decile-rank i.e. a measure that takes on ten possible values ( 0 to 1$)$ which are the within stock $P R I N$ deciles. The result shows that while the loss in information due to using a more discrete and ordinal measure does reduce the principal-trading effect $(27 \%)$, it is nevertheless quite large and significant. ${ }^{15}$

\section{E. Stock Heterogeneity:}

Given the skewed stock distribution (Figure 3), a potential concern may be that the principaltrading effect is driven by some stocks only. In particular, if this effect were present only in the smaller, less traded firms, it would reduce the economic importance of the result. Column (7) addresses this by estimating the principal-trading effect separately for the KSE 100 firms and the remaining (smaller) firms. The results show that the effect remains for the smaller firms (34\%) and, if anything, the effect is larger for the KSE100 firms. Moreover, Column (8) reestimates the effect using only the largest $10 \%$ stocks and shows that it remains as large.

\footnotetext{
${ }^{14} \mathrm{~A}$ net sale on the first day would be treated similarly i.e. if a broker sold Rs 100 worth of stock we would assume that he had to have had Rs 100 worth of capital invested. See the appendix for more details on this.

${ }^{15}$ In addition, one may wonder whether our requirement that a (cyclical) trade be classified as principal only if the buy and sells exactly match may be too restrictive or may influence the results. However, more generous measures which allow for a trade to be classified as principal as long as the buys and sells are close, give similar results. For example, allowing for a $5 \%$ or less difference gives a PRIN effect of $49.9 \%$ - hardly a change from the $48.4 \%$ effect in Table 3 column (2).
} 


\section{F. Sample Period:}

As Figure 2 shows, the market experienced a boom during the middle of our data sample. A concern may be that the principal-trading effect is driven by these overall market movements (i.e. high PRIN brokers just happened to be selling more during this period). While this concern seems unlikely, we nevertheless test for it by estimating the principal-trading effect separately in three equal sub-periods (both the PRIN and profitability measures are constructed separately in each period). Columns (9)-(11) in Table 3 (Panel B) show that the principal-trading result is present in all three periods. Moreover, the correlation between PRIN measures across the three periods is very high suggesting that brokers who trade as principal traders in a given stock continue to do so over time.

\section{G. Strategy Risk:}

A concern with our findings could be that while the principal-brokers earn a higher level return, they may be exposed to greater risk thus leading to a lower risk-adjsuted return than we obtain. However, we argue that this is unlikely. Note first that our analysis compares principal and outsider profits within the same stock and thus principal-brokers are facing the same stock-specific risk. Admittedly, there can still be strategy-specific risk within the same stock that is higher for principal-brokers than the outside investor. However, if we divide the market into principal-brokers and outsiders, since markets clear at each point in time, the level gain by one party exactly equals the level loss by the other party. In other words, it is a zero-sum game and therefore principal-brokers are not exposed to extra risk as compared to the outside investor. We acknowledge that there may still be risks of legal prosecution if a principal-broker is involved in manipulation but this does not seem common in practice.

\section{Evidence for Price Manipulation}

So far we have shown that brokers who trade on their own accounts earn significantly higher returns at the expense of outside investors trading through intermediary brokers. While the return differential is high enough to be of concern as a deterrence to the average investor from entering the market, we have no reason to believe that this differential is suspect: Principal brokers may simply have greater ability or be in a better position to time the market. This is not surprising given that the outside investor in an emerging market is unlikely to be as experienced or trained. However, 
what is of greater concern is if this differential is driven by brokers exploiting insider information or engaging in manipulative practices.

In this section we take a first step towards understanding what may be causing the large profitability differences by directly testing for a particular trade-based manipulation mechanism suggested by the institutional description, anecdotes and patterns of trades highlighted in the previous sections.

Before describing and testing the manipulation mechanism, it is important to explain why we believe the principal-trading result may be due to manipulation. Conceptually, there are a couple of reasons why one may expect that those who intend to resort to market manipulation, particularly trade-based, would be more likely to be principal-brokers. First, manipulation of prices is likely to involve frequent buying and selling of large numbers of shares in the process of generating artificial volume and price changes. Anyone interested in such an activity would first want to minimize the transaction cost of such trades. Buying a brokerage license on the stock market is the natural step to take for such an individual. Second, real time information about the movement in prices, volumes, and traders' "expectations" are all factors crucial to the success of a manipulation strategy. Having a brokerage license that allows you to sit in close proximity to other market players and monitor information in real time is a big comparative advantage. This is particularly true in an emerging market where the information technology markets are not very well developed.

\section{A. Pump-and-Dump Manipulation:}

To use Allen and Gale's (1992) classification, manipulation can be information, action and/or trade based. The first relies on spreading false information (Enron, Worldcom etc.), the second on nontrade actions that may effect stock price (such as a take-over bid) and the third, on traders directly manipulating prices through their trading behavior. The mechanism we are interested in testing is of the last type. Moreover, given the several theoretical models of trade based manipulation (see Zhou \& Mei (2003) for a review), we do not model the mechanism, but describe it in some detail and relate it to the existing theoretical literature. Amongst these models Zhou and Mei's model is closest in spirit to what we describe.

The mechanism suggested by the anecdotes and trading patterns is a "pump-and-dump" mechanism that entails brokers creating artificial excitement by trading back and forth in a stock in the hope of attracting "trend chasers" and then exiting the market profitably before the "bubble" bursts. 
Figure 6 illustrates a stylized version of this mechanism but one that we believe reflects reality reasonably well: We first classify each stock-date with a state variable $I_{B} I_{S}$, where $I_{B}$ and $I_{S}$ refer to the overall PRIN category of buyers and sellers trading the stock's stock on that date. For simplicity, assume that $I$ can take a $H$ (igh) or $L($ ow $)$ value giving four possible states for a given stock-date: $H H, L H, L L$, and $H L$. The state variable $L H$ means that the average $P R I N$ of the brokers buying the stock's stock that day is low, whereas the average $P R I N$ of the brokers selling the stock that day is high. ${ }^{16}$ The stylized mechanism works as follows: Assume we start at a point where prices are at their lowest (point A). At this stage manipulating brokers (with high $P R I N)$ trade back and forth among themselves (i.e. the state at point $\mathrm{A}$ is $H H$ ) in order to create artificial momentum and price increases in the stock. This eventually attracts outside investors with extrapolative expectations (i.e. positive-feedback traders) to start buying (branches B,C). However, once the price has risen enough, the manipulators exit the market leaving only outsiders to trade amongst themselves (point D). The state when price is at its highest is thus $L L$. This artificially high price cannot be sustained and eventually the "bubble" bursts (branches E,F) and the outside investors start selling. Once prices are low enough, the manipulators can get back into the market to buy back their stock at low prices and potentially restart another pump-and-dump cycle (point $G$ ).

Needless to say, the above mechanism is extremely stylized and it is unlikely that it can be continuously used. Moreover, it relies on the existence of momentum traders and assumes that "groups" of brokers get together to manipulate prices as opposed to an individual trader doing so. However, since we are testing for this mechanism directly, this also implies testing for these assumptions.

The mechanism implies that stock-date states can be used to predict price levels and changes. Examining price levels shows that, as in the mechanism described, price is indeed the lowest when trade is mostly between principal-brokers (state $H H$ ) and peaks when trade is between intermediaries (state $L L$ ). In particular, the normalized stock price is 106.1 when the state is $L L$, and 94.6 when the state is $H H$. The normalized price is constructed by dividing the stock price on a given day by its average during the entire sample period. The result confirms the prediction of Figure 6 that stock prices are generally at their highest in the $H H$ state and lowest in the $L L$ state.

The next and more challenging test for the price manipulation scheme described above is to

\footnotetext{
${ }^{16}$ We define high and low relative to the average PRIN value of brokers for a given stock throughout the data period: A buying index of $L$ on a date means brokers buying the firm's stock have a lower PRIN than usual for the firm.
} 
establish that principal-brokers are able to influence future prices. Specifically, we would like to identify principal-broker behavior that is able to predict future price changes. The price mechanism above suggests that this "behavior" is when the market consists mostly of principal-brokers trading amongst themselves. While we cannot identify exactly who a broker trades with, we know that on $H H$ days principal-brokers are, by construction, only trading with similar types. Thus the test would be to see whether the $H H$ state predicts future price changes. It is also worth noting that there is no reason, other than the manipulation mechanism suggested, to suspect that this state by itself should be directly related to higher future returns. In addition to $H H$ predictability, a further test that such broker behavior influences future prices artificially is if it's subsequent absence predicts a price fall i.e. as in Figure 6, the $L L$ state predicts negative returns. Columns (1)-(4) in Table 4, detailed below, present these tests and show that indeed not only do $H H$-states predict future price increases but $L L$-states also predict future price falls.

An intuitive way to conduct these tests is to construct the following hypothetical investment strategy: Imagine that during the course of a week 1 you, as an investor, observe the average state ( $\mathrm{HH}$ etc.) of all shares traded during that week. Based on this, on the first day of week 2 , you buy an equal-weighted portfolio of all stocks that belonged to a particular state, say $H H$, that week. You hold onto this portfolio for the whole of week 2, and sell it on the beginning of week 3 . Thus an "HH-strategy" would be to buy each share that had an average state of $H H$ during week 1 at the first day of week 2, sell these shares at the beginning of week 3 and simultaneously buy all shares that had an average state of $H H$ in week 2 and so on. The advantage of this construction is that if states were observable we are literally describing actual investment strategies and opportunities to consistently "beat the market". Moreover, doing so collapses our data into a single observation each week and hence we do not have to worry about correlation of returns across stocks at a given date. Autocorrelation of returns remains a potential problem but we control for that by using Newey-West standard errors.

Now we can test for the price change results by comparing the average return on the portfolios constructed using such $H H$ and $L L$ strategies. Given Figure 6, we expect that the $H H$ state would predict positive returns, while stocks in the $L L$ state last period would earn negative returns. In order to correct for overall market trends, we look at "above-market" returns for these investment strategies i.e. we subtract the overall market return in a week from the state-contingent portfolio's return that week.

Column (1) shows that an $H H$-strategy results in $0.12 \%$ higher weekly return as compared to 
the market return i.e. the $H H$-state predicts positive future returns. Column (2) shows that the $L L$-state predicts negative future returns, leading to a weekly loss of $0.20 \%$.

However, Figure 6 really makes a prediction about positive (negative) returns at the point where one is near exiting state $H H(L L)$. The idea is that when there are consecutive sequences of $H H$, the first few instances of $H H$ may not lead to positive price change necessarily, but the last $H H$ in the sequence should be a strong predictor of future returns. Columns (3)-(4) perform these more nuanced tests: Instead of holding a stock whenever its state is $H H$ or $L L$, we only hold a stock if its state is $H H$ but its future state is different from $H H$. We call such states $H H e n d$, and $L L e n d$. The results show even larger effects as expected: HHend predicts weekly gains of $0.56 \%$ and LLend losses of $0.64 \% .{ }^{17}$ As a robustness check, we repeat the price change tests (Panel B of Table 4) for only the top two deciles by market capitalization of stocks and get similar results. ${ }^{18}$

Thus these results suggest that the "pump-and-dump" mechanism that we describe above is indeed used by principal brokers to earn profits. However, this does not preclude the other explanations we suggested, including the less suspect ones such as better market timing or ability. In the next section, we take a closer look at these alternate explanations and argue that there is little support for them. Before doing so it is worth contrasting the mechanism we describe with other trade-based manipulation mechanisms and noting some aspects of feedback-trading in the data.

\section{B. Other Manipulation Mechanisms}

While we have presented direct evidence for a specific price manipulation mechanism where two or more brokers trade amongst themselves to generate artificial momentum, it is possible that there may be other such mechanisms at work.

The first such mechanism is similar to the strategic manipulation mechanisms described by papers such as Aggarwal and Wu (2003). Such mechanisms do not require colluding principalbrokers unlike the one we discussed. Instead asymmetry in information can allow even a single principal-broker to artificially move prices and make money off investors with less information.

\footnotetext{
${ }^{17}$ In addition to testing price predictability for the $H H$ and $L L$ states one may also interpret Figure 6 literally, and hypothesize that $H L$ and $L H$ states will predict negative and positive future returns respectively. While we maintain that this is too literal an interpretation of the price manipulation mechanism, for what its worth, these tests (regressions not presented) also hold - weekly returns after $H L$-states are $-0.38 \%$ and after LH-states, $0.64 \%$.

${ }^{18}$ The standard errors are higher given that we have substantially reduced the number of stocks over which we compute these returns. However, the returns to the strategies of interest, HHend and LLend, remain similar. In addition, we also tested (regressions not shown) the robustness of the Panel A results to using a more restrictive definition of high and low PRIN (categorize the top third PRIN values as high and the bottom third as low instead of splitting at the median) and all the results in Panel A hold.
} 
While this is theoretically possible, it does not seem to be supported in the data. In the trading patterns we see that principal brokers trade directly with other principals. In fact as the test in Column (1) of Table 4 shows, it is precisely these trades that lead to positive returns. Similar tests constructed by defining states based on trade-types of a single principal broker do not predict future returns (regressions not shown) i.e. it is the collusive trading behavior between different principal brokers that predicts positive future returns and not the behavior of any one broker alone.

A related mechanism that is closest in spirit to the pump-and-dump mechanism we describe in that it does not rely on informational asymmetries but is purely trade-based, is Zhou and Mei (2003). However, their model assumes that a single investor is large enough to manipulate prices. In contrast, the mechanism we test involves two or more brokers trading together to raise prices. In fact Aggarwal and Wu's (2003) examination of stock market manipulation cases pursued by the US Securities and exchange commission leads them to also conclude that "indeed, most manipulation schemes are undertaken jointly by several parties". Nevertheless, while the single trader as manipulator model is ruled out for the same reasons as the mechanism above, a slight modification of Zhou and Mei's model to allow for brokers to pool together to manipulate prices, would be consistent with our mechanism and empirical tests.

\section{Irrational Trend-Chasers?}

The above price-manipulation mechanism relies on positive feedback investment strategy assumed on the part of outside investors. Such behavior is familiar in the behavioral finance literature. Surveys indicate that often extrapolative expectations on the part of the naive trader underlies such positive feedback behavior. De Long et al (1990b), and Shleifer (2000) have hypothesized such investment strategies to explain stock market anomalies such as momentum, and bubbles. Thus our test of the manipulation cycle in Figure 6 can partly be thought of as a test for the presence of positive feedback investors in a real market setting. However, what is not clear from these tests is whether these outside investors are naive in the sense that they are consistently losing money (and therefore "irrational") or, that momentum trading is on the whole a profitable strategy. This is possible if the extent and frequency of manipulation is low and there is sufficient momentum in the market so, in equilibrium, it is profitable to be a momentum trader. While we do not take a stance on the rationality or irrationality of feedback traders, since both are consistent with the price manipulation mechanism we describe, the data suggests that momentum-trading by itself is not a profitable strategy (regressions not shown). 


\section{Alternate Explanations}

The previous section presented convincing evidence that principal brokers pool together to manipulate prices and earn at the expense of outsiders. However, to what extent is the manipulation mechanism we described the only means through which principal-brokers are making profits? While it would be naive and not empirically possible to argue that such trade-based mechanism is the only means used, we can present evidence on the likelihood of other explanations. In particular, we will consider two broad classes of alternate explanations: Market timing and Liquidity provision. At the outset, we should make clear that neither of these explanations imply the price level and returns state-predictability results that we obtained above. However, neither are these results a refutation of these explanations. Instead, the approach we take in this section is more direct - we simply attempt to understand to what extent the principal-trading result could be driven by these alternate explanations.

\section{A. Market Timing: Broker "Ability" or Private Information}

Principal brokers may earn greater profits because they are better at market timing for a variety of reasons. For example, brokers may have superior ability to predict future stock performance. Alternatively, they may have better or insider information on a stock that they can use to time the market. ${ }^{19}$ Either the ability or information story implies that brokers will buy a stock when its price is low, and sell when high. Since "buying low and selling high" by definition leads to higher profitability, the market timing explanation in general is not testable. However, the micro-nature of our data set allows us to perform some direct tests of this hypothesis.

We start with the assumption that the market timing capability of a broker (whether due to ability or information) is constant across stocks. Then a simple test of the market timing hypothesis is to include broker fixed effects in our primary regression and see if the profitability differential result remains. Column (1) in Table 5 shows that while the profitability differential changes, it is still very large at $37 \%$. Therefore, our results are not driven by systematically better market timing by the same set of brokers.

Although the above test is informative, it does not exclude more subtle market timing explanations. For example, the assumption that broker market timing capability is constant across stocks may not hold. Brokers may have a stock-varying capability to time the market. They may differ

\footnotetext{
${ }^{19}$ For example, Bhattacharya et al [2000] in a study of the Mexican stock market show that there is no public reaction to corporate news, and suggest insider trading before the news as an explanation.
} 
in their ability or access to insider information across stocks. In this case broker fixed effects will be ineffective.

We appeal to the micro nature of our data set to test for the plausibility of this more nuanced market timing explanation. Recall that in Table 1, Broker B also engaged in a series of cyclical trades we referred to as principal cycles. Can the market timing explanation be consistent with the existence of principal cycles? Perhaps a single cycle can be justified by market timing: A broker may buy 100 shares of a stock on receiving good insider news about the stock, and then sell these 100 shares next day once this news is realized. But it is extremely unlikely under the market timing hypothesis (if not impossible) that a series of such cycles may exist sequentially (e.g.. first seven trades in period 2, Table 1). As we will show later, such cycles may be consistent with other explanations, but they are not consistent with market timing explanations.

Therefore, a test for stock-varying market timing hypothesis, and the market timing hypothesis in general, would be to exclusively focus on consecutive cycles. If market timing is the dominant explanation, then consecutive cycles on their own should not be correlated with higher profitability. To perform this test, we separate the $P R I N$ measure into principal trades that consist of at least three consecutive cyclic trades, PRIN3cycle, and those that do not, but are principal-trades, PRINnon3cycle. Specifically, for PRIN3cycle we look at each day's trading for a given stockbroker and assign a value of 1 ( 0 otherwise) if it is part of a 3 cycle i.e. a sequence of only buying or selling that is exactly reversed on three consecutive trading days (e.g. Days 1-4 sequence 2 of Table 1 form one 3-cycle). PRIN3cycle is the average of this indicator over the entire trading history of the stock-broker. PRINnon3cycle estimates the "remaining" part of PRIN. Thus a trade which is classified as PRIN on a given day must either be a PRIN3cycle OR a PRINnon3cycle.

If market timing is the only explanation for our results then the coefficient on PRIN3cycle should not be significant, given that such trades are very unlikely to reflect broker ability or information. Column (2) in Table 5 however, shows that this is not the case - The PRIN3cycle coefficient is $31 \%$ and remains highly significant. Note that although the coefficient on PRINnon3cycle is larger (51\%), this partly reflects the stringent "repeat" cyclical trading definition used.

To conclude, better market timing is unlikely to be a complete explanation for the principaltrading effect given the above results and trading patterns in the data: Not only do the results remain robust to the inclusion of broker fixed effects but the profitable trading patterns, such as back and forth buying and selling by two brokers, are very hard to reconcile with legitimate portfolio optimization and market timing. 


\section{B. Liquidity Provision}

The second class of alternate explanations is that the principal-trading effect may reflect a premium for liquidity provision. In KSE liquidity is provided through standard market-making activity or through an after-market repo transaction facility referred to locally as "badla" trading.

\section{B-1. Market Makers}

Table 2 showed that the acyclic principal buy and sell trades were likely to take place on relatively low-turnover days suggesting that the principal-trading result may reflect the return to marketmaking. While there is little disagreement that market makers earn a premium for providing liquidity, what is not clear is why market makers are more likely to engage in principal-trades i.e. have a high $\operatorname{PRIN}$ value. Nevertheless, we can directly test for a liquidity explanation by controlling for broker attributes that are correlated with liquidity provision. Since we controlled for broker fixed effects in column (1), it is clear that any stock-invariant broker attributes that lead a broker to engage in liquidity provision, such as wealth or size, cannot explain our results.

One may still appeal to a stock-varying liquidity explanation i.e. brokers differ across stocks in their ability to provide liquidity. We test for such an explanation by controlling for two stock-broker level attributes likely to be correlated with liquidity provision. The first measure we use is the share of a given stock's volume traded by a given broker during the sample period. Columns (3) in Table 5 shows the robustness of our results to the inclusion of this liquidity control.

Second, one could argue that the return to liquidity provision primarily accrues on days on which there is low-turnover to begin with i.e. the majority of traders want to buy (sell) the stock but there are not enough traders willing to sell (buy), and on these days a broker can offer to be this seller (buyer). It may be the case that such a broker engages in a Principal-trade (i.e. will only buy or sell) since he is trading to clear the "net" position. However, this explanation is not consistent with the result in Table 2 that cyclical principal-trades in fact happen on very high turnover days. More importantly, column (4) controls for the average stock-turnover on the days that a given stock-broker trades, and shows that the principal-trading result is unaffected.

\section{B-2. "Badla" Trades}

Besides the results in columns (3) and (4), another problem with the market maker explanation is that it cannot explain the profitability of brokers who engage in cyclical trading patterns. How- 
ever, there may still be a liquidity-based institutional explanation for observing cycles. Such an explanation is based on repo or "Badla" trades. "Badla" is a local term for a forward trading facility used and recognized by the KSE (see Berkam \& Eleswarapu (1998) for Badla in the Bombay Stock exchange). A Badla transaction is essentially a repo transaction carried out in a separate after-hours market where the borrower who "takes" the badla from a badla broker carries forward his security exposure from the current settlement period to the next one, by sale of his position in the present period and its repurchase in the subsequent settlement period at a predetermined price differential. Thus badla traders will appear as cyclical principal-traders and hence be assigned a high PRIN measure.

While badla-trades may explain the cyclical patterns, there is no reason to suppose that those who engage in badla trading also make more trading-profits: The return for providing Badla, while similar to a liquidity premium, is in fact paid in terms of an explicit badla commission (set daily in the after-hours badla market) and is therefore not reflected in the trading profits. Thus, in the absence of a liquidity premium explanation, a badla-trader can only earn higher trading profits if he strategically uses the badla i.e. he exploits the fact that he may be able to affect future stock prices by offering or withholding the badla facility.

The simplest way to test for such an explanation would be to explicitly identify badla trades (they are conducted in a special after-hours market). Unfortunately our data does not record these trades separately i.e. it does not distinguish between a badla transaction and an actual trade in the (ready) market. However, if we impose the plausible condition that badla/repo transactions are reversed then one can identify them by separating cyclic and acyclic principal trades as in Table 2 and then constructing analogous measures to PRIN at the broker (stock) level: PRINcycle and PRINnoncycle. ${ }^{20}$ The former includes both badla brokers and principal brokers (i.e. all Principal Cycle trades), while the latter includes only Principal Buy and Sell trades and is thus less likely to include badla brokers.

If badla-trading is indeed responsible for the principal-broker effect then acyclic principal-

\footnotetext{
${ }^{20}$ Specifically, for PRINcycle we look at each day's trading for a given stock-broker and assign a value of 1 (0 otherwise) if the broker either only bought or only sold shares that day AND this buy (sell) is exactly equal to the sell (buy) the next time he trades (and he also only sells or buys that day). PRINcycle is the average of this indicator over the entire trading history of the stock-broker. PRINnoncycle estimates the "remaining" part of $P R I N$. It looks at each day's trade for a given stock-broker and assigns a value of 1 ( 0 otherwise) if the usual PRIN condition holds (i.e. the broker either only buys/sells or buys and sells the same amount on a given day) AND there is no "pure" cycle (i.e. today's buy/sell are not the same as the next trade's sell/buy - "pure" signifies that in addition at least one side of the trade - buy or sell - is zero). PRINnoncycle is the average of this indicator over the entire trading history of the stock-broker. Thus a trade which is classified as $P R I N$ on a given day must either be a PRINcycle OR a PRINnoncycle. Note however, the eventual PRINcycle and PRINnoncycle measures need not be mutually exclusive as they are averaged over all trades of the stock-broker.
} 
trading should not be profitable. Column (5) in Table 5 presents the results of this regression and shows that the coefficients on both PRINcycle and PRINnoncycle are large and significant (36\% and $55 \%$ respectively).

Now let us revisit the findings in Table 5 in light of the price manipulation explanation. We have argued above that explanations relying solely on either market making or liquidity are hard to reconcile with the results, in particular the cyclical patterns of trading and the profitability of brokers involved in principal cycles. Such trade patterns do not seem consistent with any reasonable portfolio re-balancing strategy, or trading based on real information. On the other hand, the back and forth buying and selling by the broker in column (2) of Table 1 is highly suggestive of attempts at price manipulation: Such cycles arise naturally in direct manipulation schemes (brokers pair up and buy and sell rapidly to each other to create excitement) although one can imagine such manipulation being carried out in acyclical ways as well (e.g. a broker may buy and sell differing amounts or buy sequentially for a few periods with another broker buying). Thus both types of principal trading, cyclic or acyclic, arise naturally under market manipulation. Moreover, one would expect that, to the extent such types of principal trading reflect manipulation, they will all be profitable: Thus the results in Table 5, particularly Columns (2) and (5), are consistent with the market manipulation hypothesis.

While we acknowledge that principal brokers may also employ other means for generating higher returns; (i) our results on the trading patterns used by principal brokers, (ii) direct tests verifying the price manipulation mechanism used by principal brokers, and (iii) little evidence for alternate explanations, all lead us to conclude that market manipulation is indeed an important part of what explains why principal-brokers earn high returns off outsiders.

\section{Concluding Remarks}

This paper uncovered unusual trading patterns and systematic profitability differences arising from trades between brokers and outside investors in emerging markets. While market timing and liquidity based explanations could account for some of the results, we have argued that the evidence is indicative of manipulation of stock prices by collusive brokers.

How significant are these manipulation-based rents, particularly in relation to what brokers earn by trading "honestly" i.e. by intermediating for outside investors? While it is hard to come up with precise numbers, we can provide estimates by making assumptions about trading behavior 
and brokerage commissions. Specifically, we assume that a fraction $P R I N$ of a broker's trades in a given stock are manipulative and a fraction $1-P R I N$ are intermediary trades. We can then arrive at estimates of earnings by using a $50 \%$ return on the manipulative trades (a conservative estimate of the PRIN effect) and a $1 \%$ brokerage commission (the average commission rate in the KSE) on intermediary trades. The former gives us what the broker earns from manipulation in a given stock and the latter his earnings (i.e. total brokerage commission) from honest trading in the stock. ${ }^{21}$ We can then compute a broker's total manipulation and honest trading earnings by summing the respective numbers across all the stocks he trades in.

Doing so reveals a couple of interesting findings. First, manipulation rents comprise a significant part of the overall market $-44 \%$ of total broker earnings in the market. ${ }^{22}$ Moreover, as discussed earlier these rents are likely to be an underestimate. Second, examining the earnings from honest and manipulative activity for each broker reveals that most brokers are earning significant manipulation rents. Figure 7 gives the distribution of the share broker's earn through manipulation and shows that most brokers are clustered around the single mode (40\%). This in turn has implications for regulation since it implies that rather than try and focus only on a few brokers, regulation must correct for the presence and extent of manipulation in general.

The broader question then raised by our results is how important are the market-inefficiencies, identified in this paper, from a country's financial development perspective? Our view is that in terms of direct costs, the large transfer of wealth from outsiders to insider manipulators is likely to significantly discourage how much and how many outside investors choose to invest in the market. The presence of manipulators and naive traders imposes large participation costs for rational and sophisticated agents trying to either invest or raise capital in equity markets. Such participation costs form an important piece in solving the puzzle of financial under-development. If manipulation becomes more difficult as the number of players and the size of the market increases, then there is a possibility of multiple equilibria: One with excessive manipulation and a small market size, and another with little or no manipulation and a large market size. Furthermore, the manipulation activity we document can be responsible for excessive volatility in the market and in turn impose additional participation costs.

An important agenda for future research is to understand and document what additional mechanisms used by market intermediaries may increase the participation costs and lead to excessive

\footnotetext{
${ }^{21}$ Specifically, manipulation return for broker B in stock $\mathrm{S}$ is $0.5 * P R I N_{S B} *$ Average-Capital ${ }_{S B}$ and honest return for broker B in stock $\mathrm{S}$ is $0.01 *(1-P R I N) *$ Value-Traded $_{S B}$

${ }^{22}$ Annual revenues are estimated to be Rs 6 billion from manipulation and Rs 7.6 billion from honest trading.
} 
volatility in these markets, as documented by Kindleberger in his seminal work "Manias, Panics, and Crashes" (1978). Such work will lead to a better understanding of what reforms are successful in limiting the misgovernance of markets by intermediaries. Such reforms may include a greater presence of independent members (non-brokers) in the exchange's board of directors; facilitating entry and competition amongst brokers including the setting up of new exchanges; better systems of surveillance; tighter enforcement of existing and new regulation, such as stricter margin/capital adequacy; and information disclosure requirements, that protect outside investors and prevent undesirable activities in the market.

Our results also suggest that, to the extent that a significant part of the market turnover reflects such manipulative practices, increased market turnover is unlikely to either lead or even reflect overall growth in the economy. Thus in trying to find positive correlations between market turnover and growth using cross-country data (e.g. Levine and Zervos, (1998)), emerging economies like Pakistan (and Figure 1 suggests there may be several others) appear as outliers. However, we should be careful in drawing inferences: Our results do not imply that financial markets have little to contribute to growth but that observing an active market should not automatically lead us to conclude that such a role is being played.

Identifying inefficiencies like market manipulation and the resulting significant rents accruing to individuals can help begin to answer the more fundamental political economy question of why countries fail to adopt and implement good governance and other laws needed to strengthen equity markets. Even if it is obvious what reforms need to be taken to improve efficiency, since such reforms are likely to limit manipulation, they will be resisted by the conspiring brokers. This will be the case when, in the post-reform improved equilibrium, one cannot guarantee these brokers a large enough share of the pie i.e. the Coase theorem no longer holds. This seems to be the case in Pakistan where efforts by the SECP to initiate reforms have met with strong political opposition by lobbies working on the brokers' behalf.

To conclude, since the rent-seeking activities identified in this paper are likely to occur in newer and shallower emerging markets, they can in turn be responsible for limiting the depth and size of such markets leaving them in "infancy traps" in the absence of a positive reform. The concern is that equity markets, whose job is to facilitate real economic activity, may remain as phantom markets that serve little economic purpose. 


\section{Appendix: Construction of $A R R$ measure}

This appendix describes how our main outcome measure, the Annual Rate of Return $(A R R)$ is calculated for a given Stock-Broker.

We start with the simple example in Table A1. Columns (1) through (3) give the trading history (10 actual trading days) of a broker in a particular stock. For each day we can calculate the "net shares" of the given stock bought by the broker (column (4)), and then keep track of the overall "inventory" of the broker by summing all past net trades (column (5)). ${ }^{23}$ To be able to compute the annual rate of return in this example, we first need to compute (a) the overall profit earned by the broker, and (b) the average capital needed by the broker to earn this profit.

Before calculating the overall profit, we first need to address what to do with the stock inventory remaining at the end of period. For the $A R R$ measure used in the paper, we choose the simple rule of liquidating the end of period inventory at the prevailing market price. Below we also mention an alternate measure but since the results are similar, we retain the simpler $A R R$ measure. Treating the value of net shares sold on a given day as revenue (column $(6))$, and the net shares bought a given day as investment (column (7)), we can compute net profit as the difference between revenue and investment. Column (9) computes the net running profit by differencing out the sum of investments from the sum of revenue up to that point. Thus the running profit at the end of period is the total profit (or loss) earned by the broker over the entire period.

Next to calculate the average capital needed by the broker over the sample period, we first need to compute the capital needed at any given point in time. The capital needed at any given point in time is the value of the net inventory holdings of the broker at the time minus any profits he may have accumulated up to then. This is given by column (10). The average capital needed is then a time-weighted average of the capital computed in column (10).

The overall rate of return in this example is then simply total net profit divided by the average net capital used. This in Table A1 this return is $96 \%$ for the 10 trades shown. Depending on the duration this trading period we then annualize these returns to obtain the $A R R$ measure.

The second measure of the annual rate of return, $A R R 2$, is meant more as a robustness check on our first: Instead of imposing that the broker clear his position by a forced liquidation on the last trading date of the stock, we "net out" his end net position. Effectively we are forcing the broker to earn 0 profits on his ending position. To illustrate this consider the example in Table A1 again. Note that on date 7 the broker has a net "inventory" of exactly 0 and after this date, on net, each trading day he only accumulates shares. The ARR2 measure will ignore this last accumulation and create a "new" trading history for the broker in which we assume that he never trades after date 7. In our simple example this implies only looking at the date 1-7 trades of the broker. ${ }^{24}$ Then $A R R 2$ is calculated like $A R R$ on this new "netted" series. However, as expected, since both $A R R$ and $A R R 2$ are highly correlated, our results do not depend on which is used. We therefore stick to the simpler $A R R$ measure in the paper.

\footnotetext{
${ }^{23}$ Note that this "inventory" is calculated using the observed trading history of the broker during our sample period. Since we are only concerned with estimating returns of the broker accrued by trading activity during our sample period, it does not matter what his starting inventory level was (i.e. how many shares he held before his first observed trade).

${ }^{24}$ In a more realistic example we may have to "split" a day's net trade in order to exactly net out the broker's actual ending position.
} 


\section{References}

[1] Acemoglu, D. and Simon Johnson, 2003. "Unbundling Institutions", NBER Working Paper \# 9934.

[2] Acemoglu, D., S. Johnson, and J. Robinson, 2002. "Reversal of Fortune: Geography and Institutions in the Making of the Modern World Income Distribution" Quarterly Journal of Economics, v117, n4 1231-94.

[3] Acemoglu, D., S. Johnson, and J. Robinson, 2001. "The Colonial Origins of Comparative Development: An Empirical Investigation," American Economic Review, v91, n5 1369-1401.

[4] Aggarwal, R. and G. Wu, 2003. "Stock Market Manipulation - Theory and Evidence", Tuck School of Business Working Paper.

[5] Allen, F., and D. Gale, 1992. "Stock-Price Manipulation", Review of Financial Studies, 5, 503-529.

[6] Bekaert, G. and Campbell R. Harvey, 1997 "Emerging Equity Market Volatility", Journal of Financial Economics 43, 29-77.

[7] Berkman, H. and V. R. Eleswarapu. 1998. "Short-Term Traders and Liquidity: A Test Using Bombay Stock Exchange Data" Journal of Financial Economics v47, n3 (March): 339-55.

[8] Bertrand, M. ; Mehta, P. and S. Mullainathan. 2002. "Ferreting Out Tunneling". Quarterly Journal of Economics, 117(1), 121-148.

[9] Bhattacharya, Utpal; Daouk, Hazem. 2002 "The World Price of Insider Trading" Journal of Finance v57, n1 (February): 75-108.

[10] Boone, P. ; Breach, A. ; Friedman, F and S. Johnson. 2000. "Corporate Governance in the Asian Financial Crisis", Journal of Financial Economics, v58, n1-2, 141-86.

[11] De Long, J. B.; Shleifer A.; Summers, L. and R. Waldmann. 1990a. "Noise Trader Risk in Financial Markets". Journal of Political Economy 98, 703-738.

[12] De Long, J. B. ; Shleifer, A. ; Summers, L. and R. Waldmann. 1990b. "Positive Feedback Investment Strategies and Destabilizing Rational Speculation", Journal of Finance 45, 375395

[13] Fisman, R. 2001. "Estimating The Value of Political Connections", American Economic Review, v91, n4, 1095-1102.

[14] Glaeser, E., Johnson, S., Shleifer, A., 2001. "Coase versus the Coasians", Quarterly Journal of Economics 116, 853-899.

[15] Gordon, J. S. 2000. "The Great Game: The Emergence of Wall Street As a World Power 1653-2000". Touchstones Books.

[16] Johnson, S., and T. Mitton, 2003, "Cronyism and Capital Controls: Evidence from Malaysia". Journal of Financial Economics, v67, n2, 351-82.

[17] Khanna, T and Sunder, S. 1999. "A Tale of Two Exchanges", Harvard Business School Case Study. 
[18] Kindleberger, C. 1978 "Manias, Panics, and Crashes: A History of Financial Crises", John Wiley \& Sons; 1st edition.

[19] La Porta, R., Lopez-de-Silanes, F., Shleifer, A., 2003. "What works in Securities Laws?", NBER Working Paper \# 9882.

[20] La Porta, R., Lopez-de-Silanes, F., Shleifer, A., Vishny, R., 1997. "Legal determinants of external finance", Journal of Finance 52, 1131-1150.

[21] La Porta, R., Lopez-de-Silanes, F., Shleifer, A., Vishny, R., 1998. "Law and finance", Journal of Political Economy 106, 1113-1155.

[22] La Porta, Rafael, Florencio Lopez-de-Silanes, Andrei Shleifer, and Robert W. Vishny, 2000, "Investor protection and corporate governance", Journal of Financial Economics 58, 3-28

[23] La Porta, R ; Lopez-de-Silanes, F ; Shleifer, A and R. Vishny. 2002 "Investor Protection and Corporate Valuation", Journal of Finance, v57, n3, 1147-70.

[24] Morck, Randall, Bernard Yeung and Wayne Yu. 2000. The Information Content of Stock Markets: Why Do Emerging Markets Have Synchronous Stock Price Movements? Journal of Financial Economics. 58(1) Oct. 215-260.

[25] Shleifer, A. and D. Wolfenson, 2002. "Investor Protection and Equity Markets", Journal of Financial Economics, v66, n1, 3-27.

[26] Shleifer, A. 2000 "Inefficient Markets: An introduction to Behavioral Finance", Oxford University Press.

[27] Shleifer, A. and R. Vishny. 1997 "Limits of Arbitrage". Journal of Finance 52, 35-55.

[28] Zhou, C. and J. Mei. 2003. "Behavior Based Manipulation", NYU Stern School of Business, Working Paper \# 03028. 
Figure 1: Market Size \& Turnover across Countries
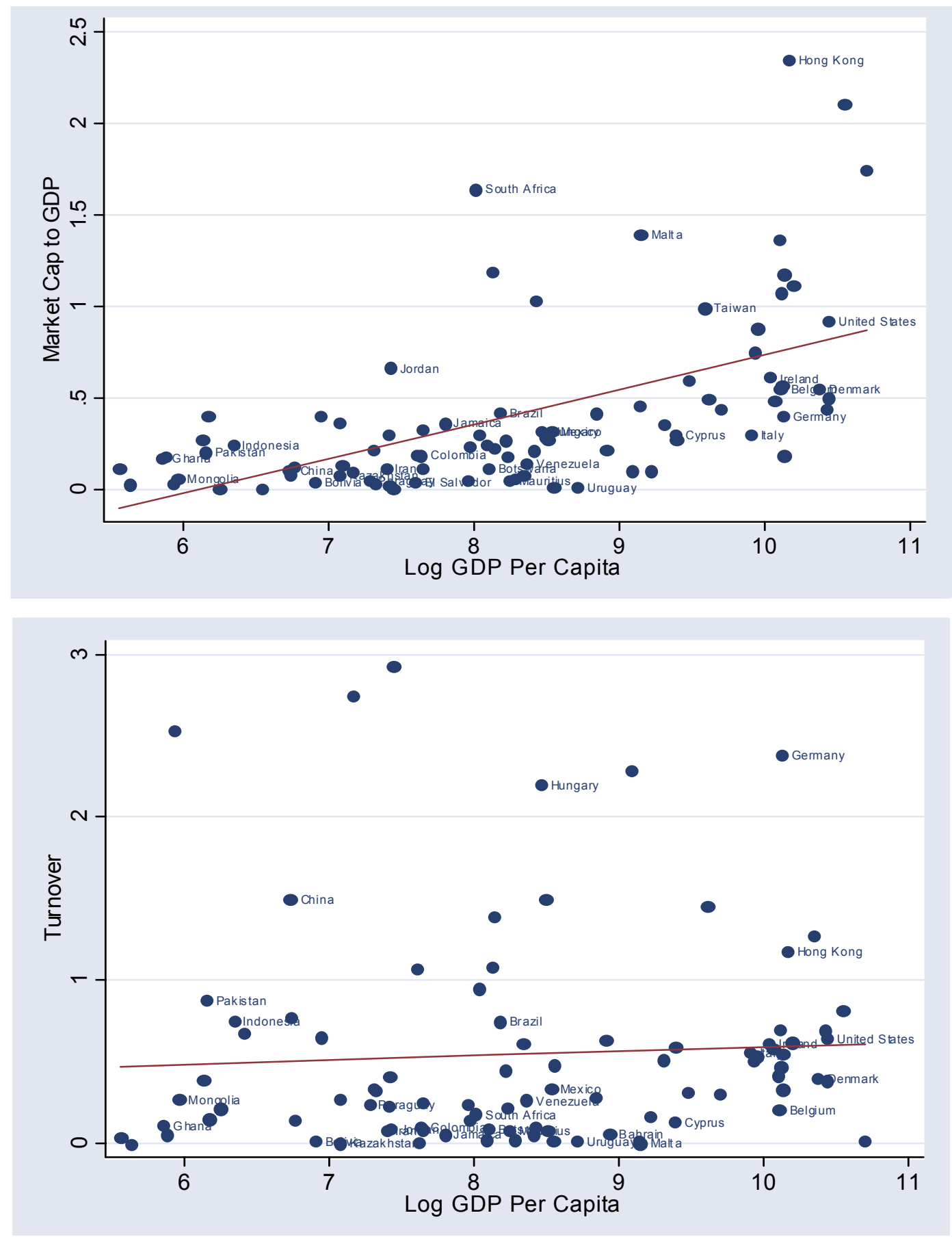

MC/GDP Outliers not shown: Bahrain=9, Namibia $=8.9$, Iceland $=8.4$

Turnover Outliers not shown: Ecuador=31, El-Salvador=11.1, Taiwan=4.3

Every Third Country in the list below starting from Ghana is labeled above (list sorted by GDP per capita):

Nigeria, Tanzania, Ghana, Kenya, Bangladesh, Mongolia, Moldova, India, Pakistan, Zimbabwe, Armenia, Indonesia, Uzbekistan, Ukraine, China, Honduras, Sri Lanka, Bolivia, Philippines, Morocco, Kazakhstan, Ecuador, Swaziland, Paraguay, Egypt, Bulgaria, Iran, Russia, Romania, Jordan, Guatemala, Macedonia, El Salvador, Thailand, Namibia, Colombia, Tunisia, Peru, Jamaica, Latvia, Lithuania, South Africa, Turkey, Panama, Botswana, Malaysia, Estonia, Brazil, Slovakia, Lebanon, Mauritius, Costa Rica, Poland, Venezuela, Croatia, Chile, Hungary, Czech Rep, Trinidad and Tobago, Mexico, Zambia, Oman, Uruguay, Saudi Arabia, Argentina, Bahrain, South Korea, Barbados, Malta, Slovenia, Portugal, Cyprus, Greece, New Zealand, Taiwan, Spain, Israel, Italy, Australia, Canada, Ireland, France, United Kingdom, Belgium, Singapore, Finland, Germany, Netherlands, Austria, Hong Kong, Sweden , Iceland, Denmark, Norway, Japan , United States, Switzerland, Luxemburg.

Data Source: Bhattacharya and Daouk [2002]. 
Figure 2: KSE100 Index $(\log )$ June 1997-March 2002*

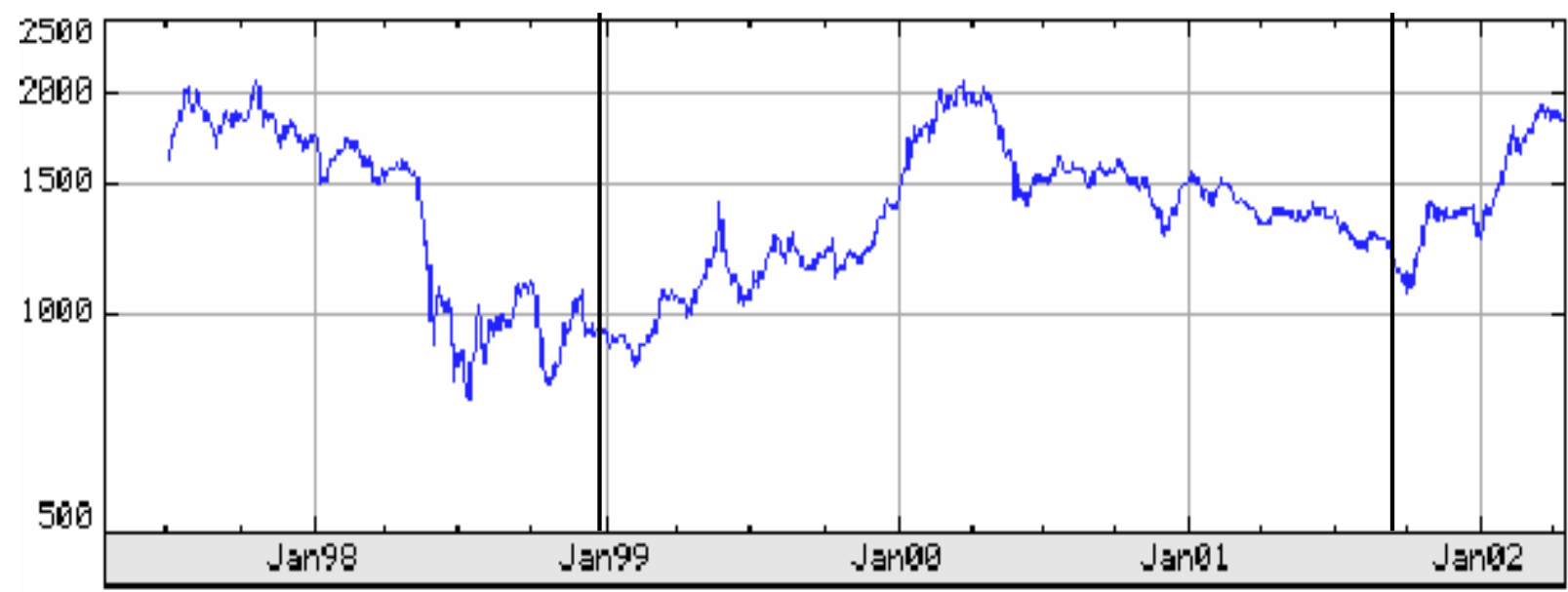

*The dark vertical lines in the figure above indicate the period for which we have broker-firm level daily trading data.

Figure 3: Cumulative Share of Market Capitalization and Turnover by Firm $\$$

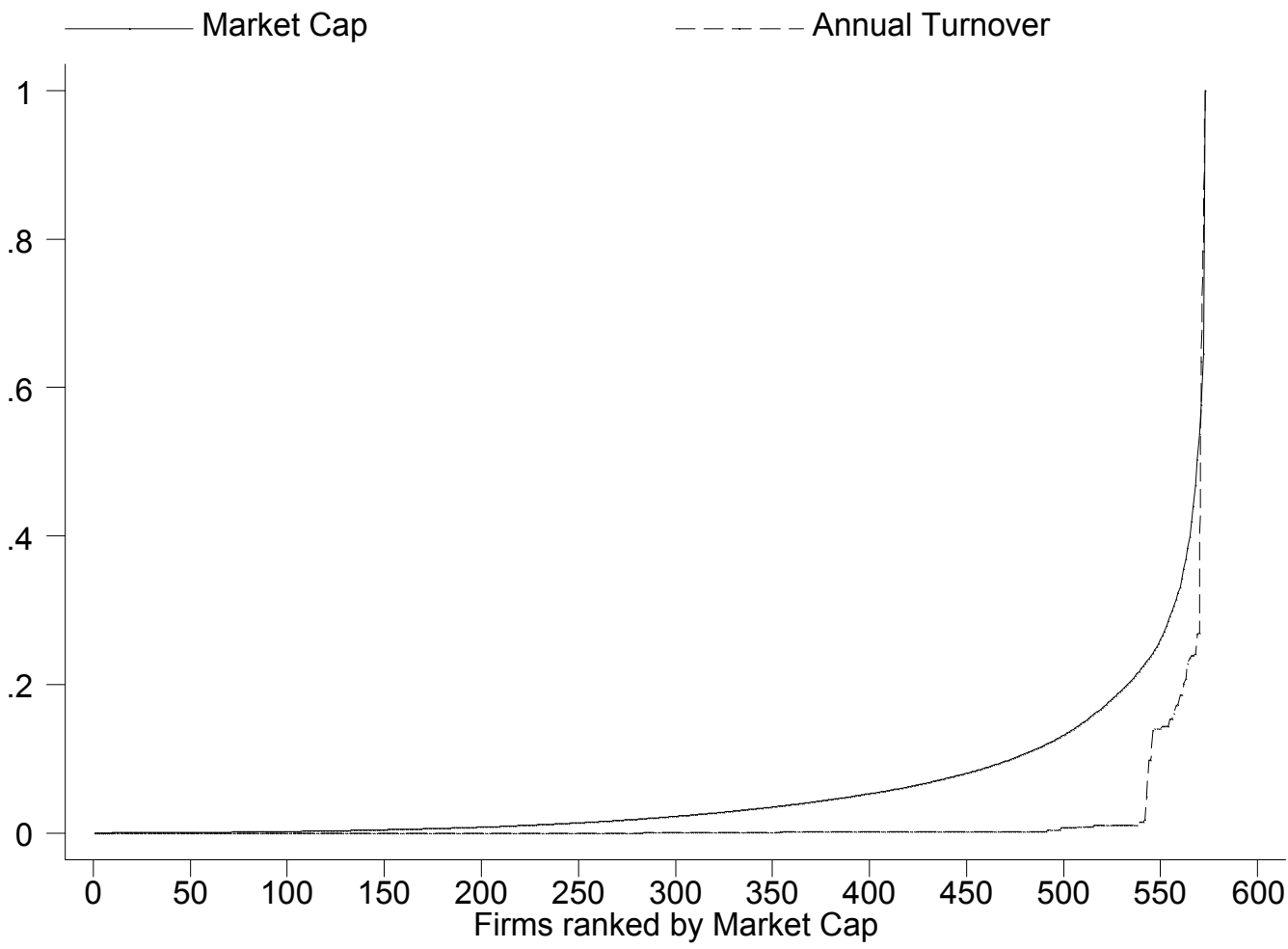

$\$$ Market Capitalization for the firms is the average over our sample period and the annual turnover for each firm is for the year 2000. While we have turnover for all firms in our sample, since we only have market capitalization for 575 of those firms, to be consistent the above CDFs are only for these firms. However, from our turnover numbers we know that these missing (market cap) firms are small and therefore won't affect the above CDFs qualitatively. 
Figure 4a: PDF for Broker Size

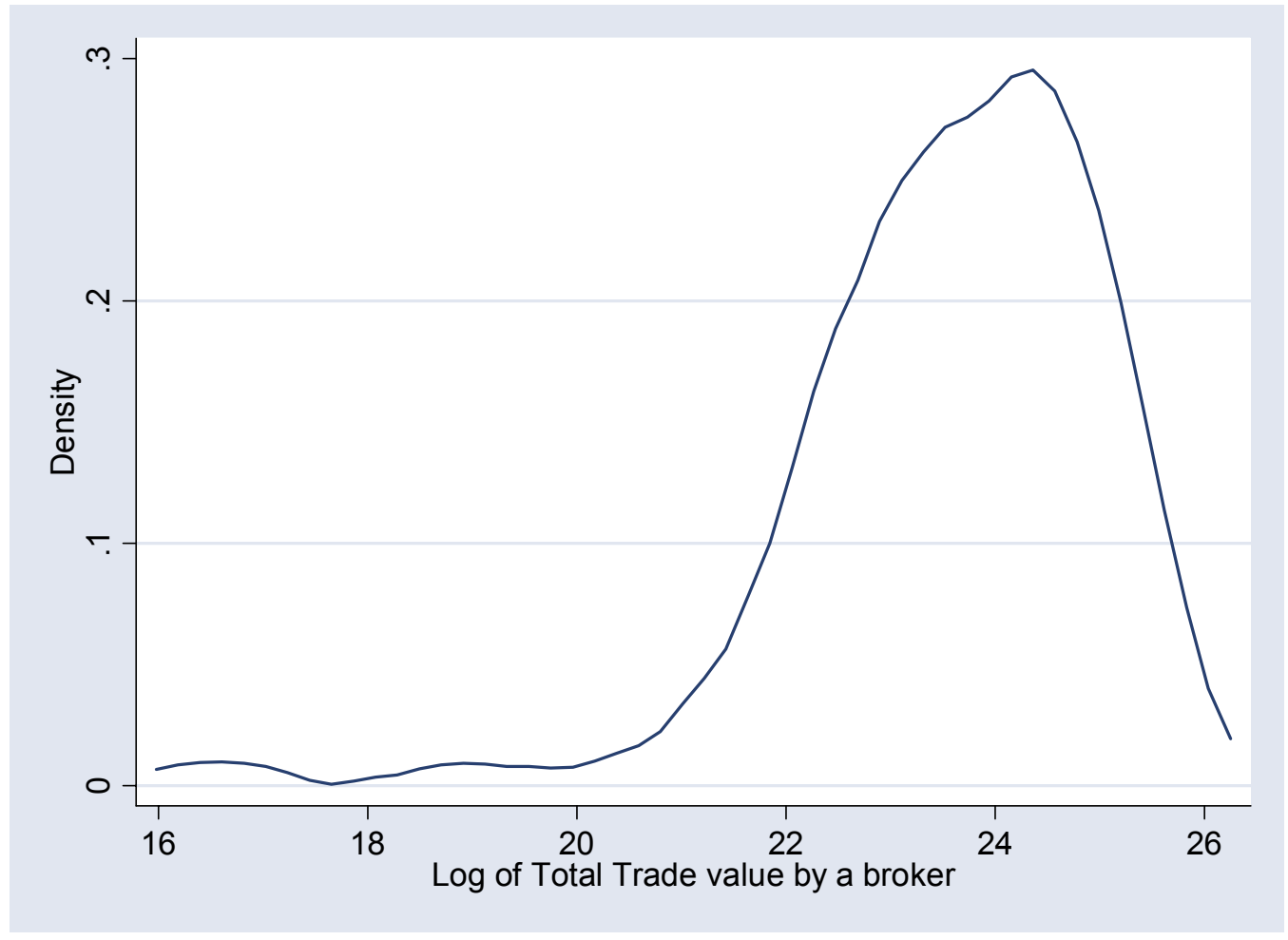

\# Broker Size is proxied by the natural logarithm of the total trade value (value of all purchases and sales) of the broker during our sample period.

Figure 4b: PDF for Broker Coverages

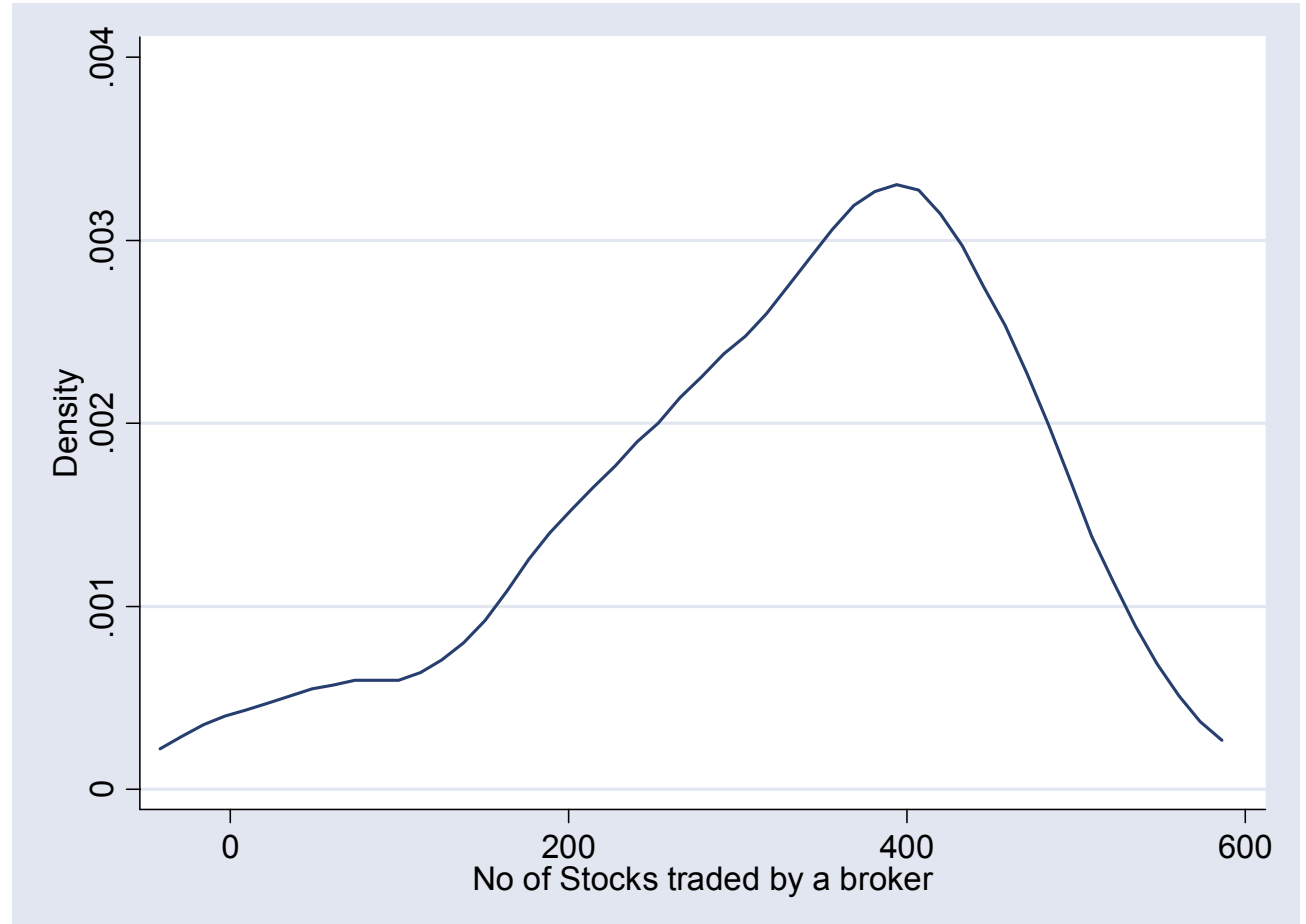

${ }^{\$}$ Broker Coverage is the number of different stocks the broker ever traded in during our sample period 


\section{Figure 5: Principal-Trading Profitability}

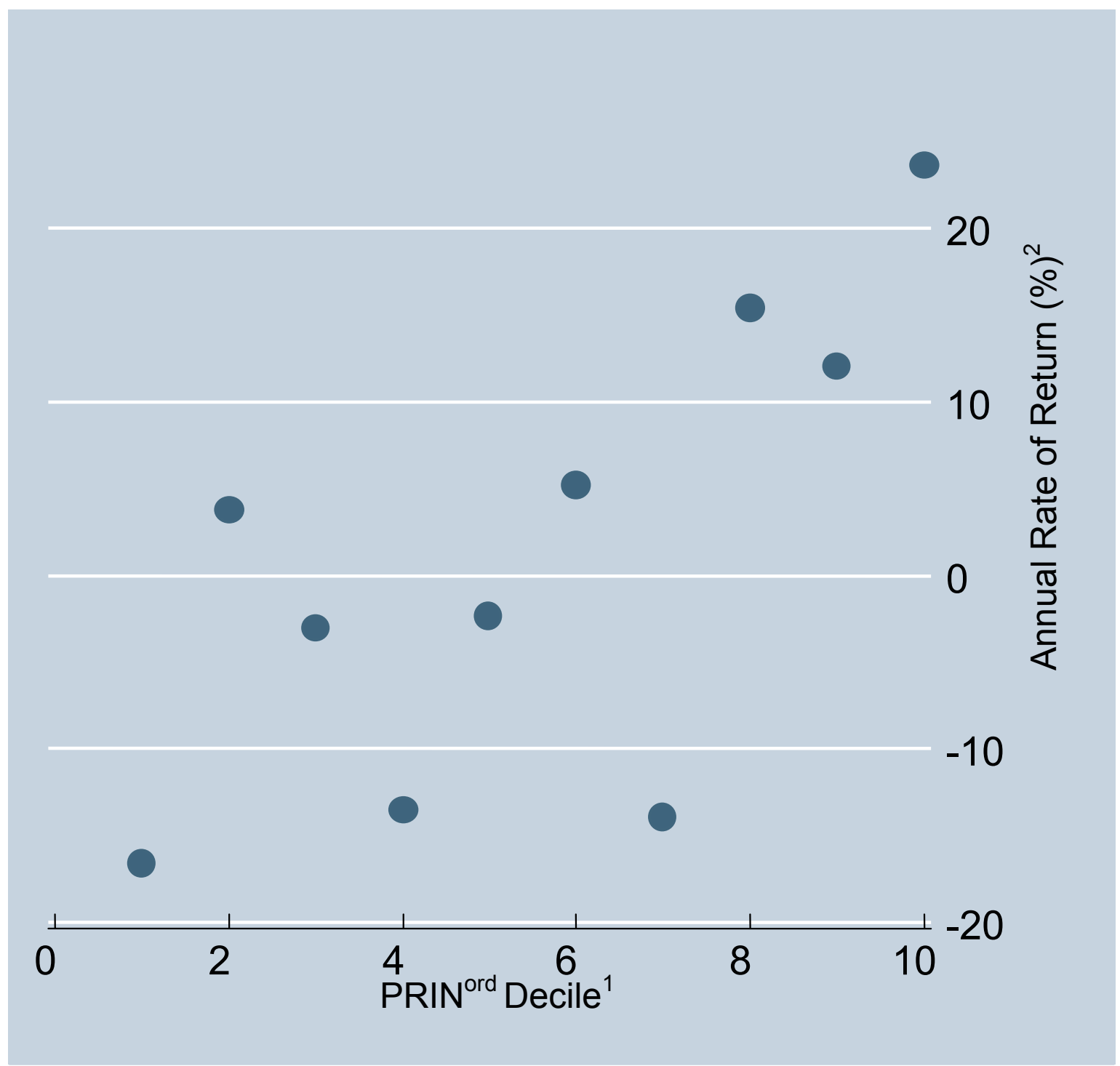

${ }^{1}$ PRIN $^{\text {ord }}$ is the percentile ranking of PRIN within each stock. For any given stock, we order brokers according to their PRIN rank in that stock. Then each broker is given a value according to the decile in the PRIN distribution he belongs to. Recall that PRIN is a measure of the "principalness" of a stock-broker as explained in Table 1.

${ }^{2}$ The Annual Rate of Return is an aggregate measure. This means we first sum all the level trading profits of stockbrokers for a given PRIN ${ }^{\text {ord }}$ decile, and then divide this profit by the total capital used by all these brokers. This gives us the return per dollar invested by the brokers. 
Figure 6: Trading Cycles- a hypothetical example

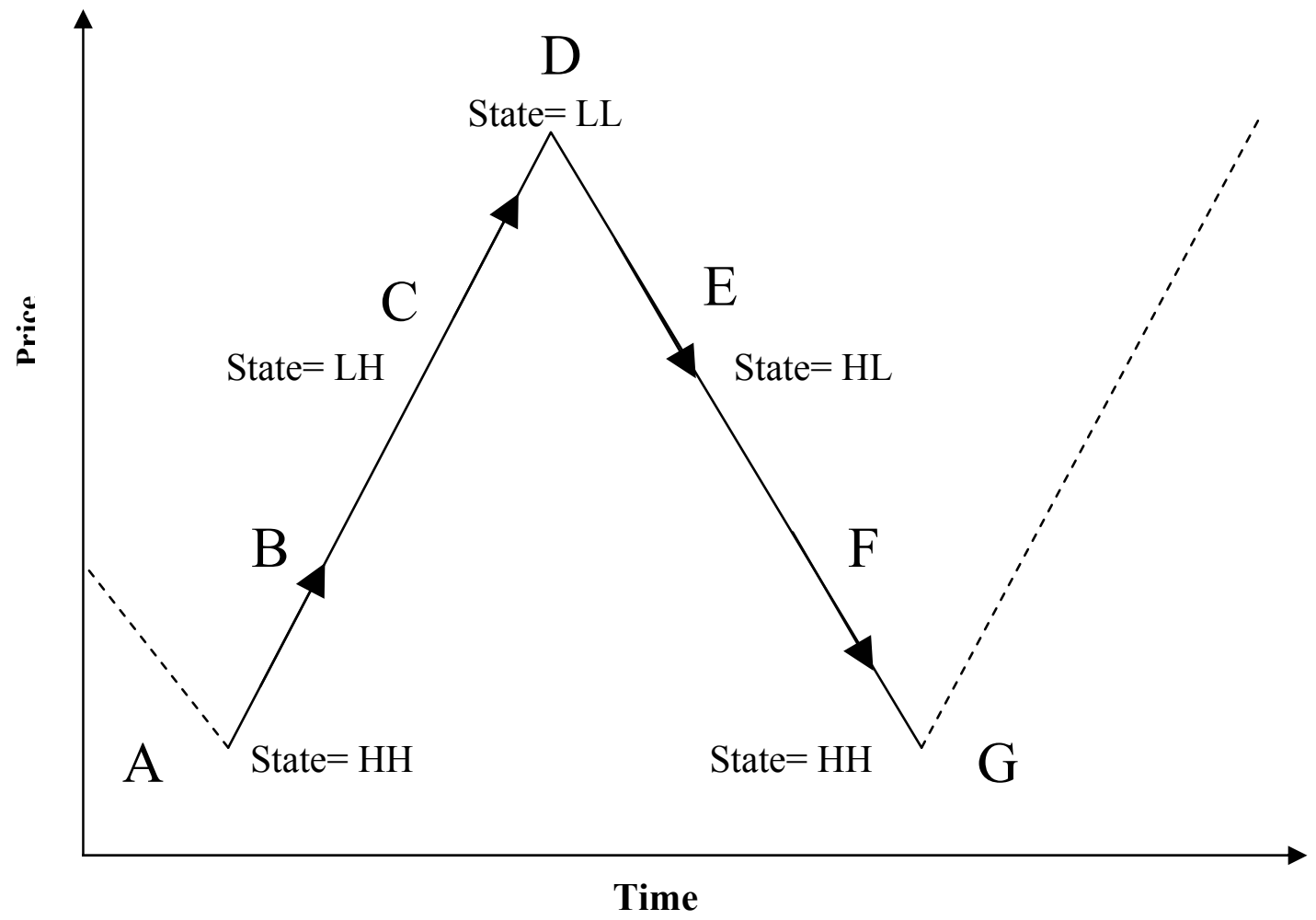

Key

A: Naïve traders are out of the market. Manipulators trade among themselves to raise prices. State $=\mathrm{HH}$.

B: "Artificial" price increases attracts naïve/positive feedback traders.

C: More naïve traders enter, as manipulators sell their last remaining stock. Some naïve investors also start selling to other naïve ones. State $=\mathrm{LH}$

D: Price reaches its peak. Manipulators have sold everything to the naïve investors. With the manipulators out, the price starts dropping. State $=\mathrm{LL}$

F: When price drops sufficiently, manipulators start buying again. State $=\mathrm{HL}$

F: Price drops further. Manipulators start buying. $P b=\mathrm{H}, P s=\mathrm{L}$

G: Cycle restarts (as in A) 
Figure 7: Manipulation Rents as a Percentage of Total Broker Earnings (PDF)

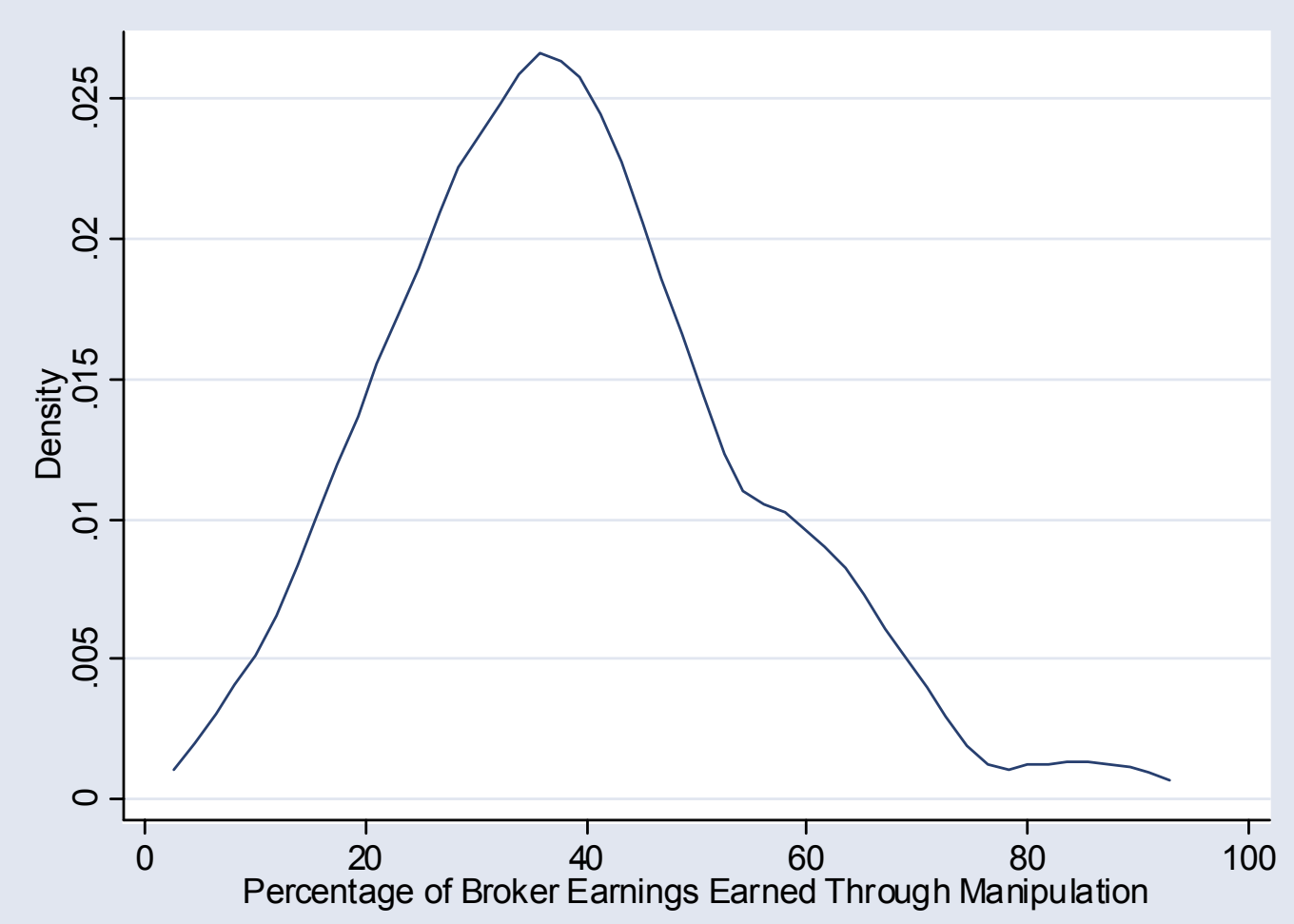

Total Broker Earnings are made up of: (i) "manipulation rents" computed using a 50\% return on trading done by broker on their own behalf (our conservative estimate in the paper), and (ii) "brokerage commissions" computed using a 1\% commission rate on the value of trading done by a broker on behalf of outsiders. 
Table 1: Principal and Intermediary Brokers Trading - An Example

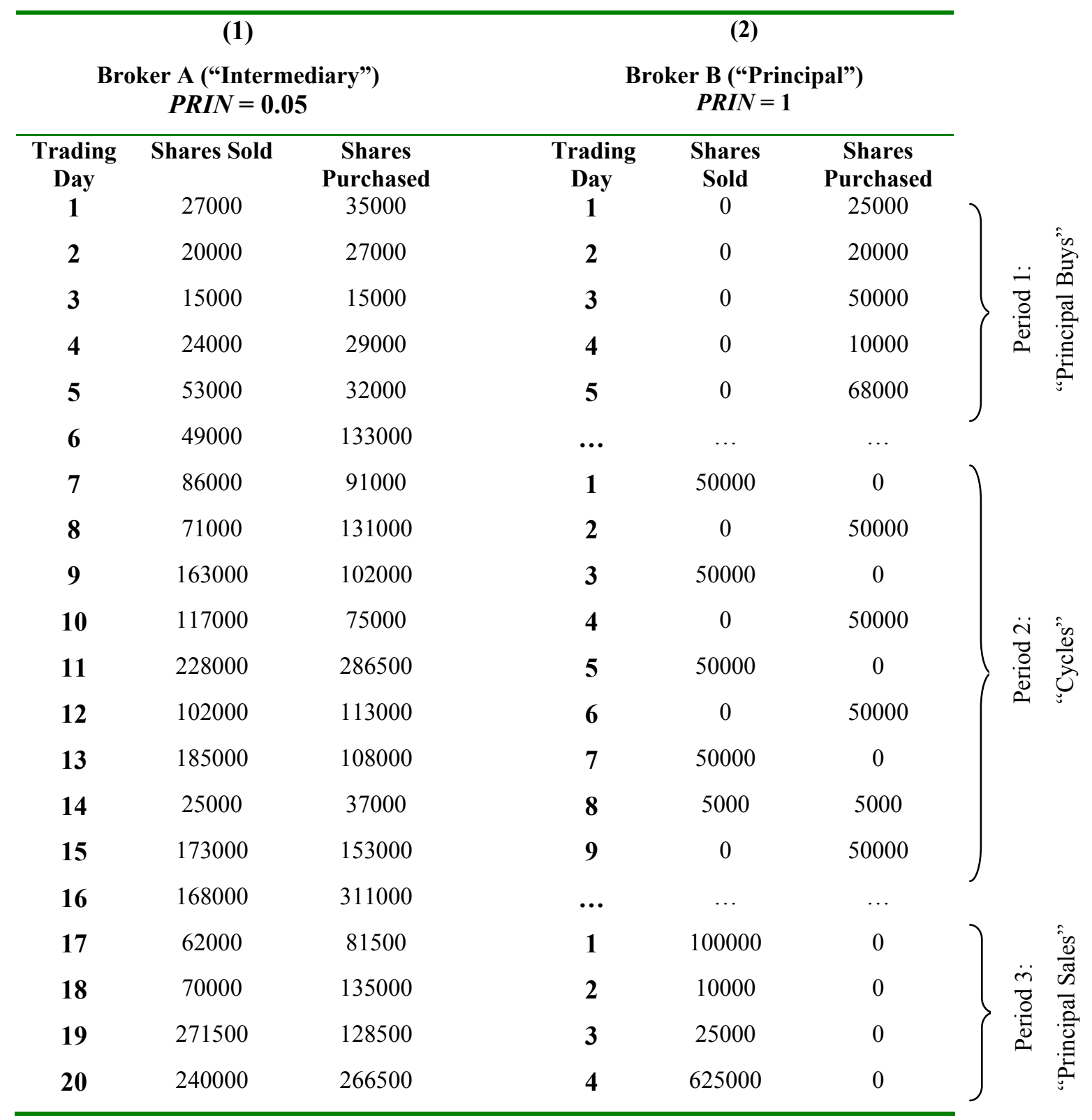

The table gives a snapshot of our original data set: We provide 20 trades for two different brokers trading the same stock. Each trade is at the day level, representing the total number of shares bought and sold by the broker during the entire day. The two brokers have very different trading patterns, which are representative of our data. The broker in column (1), (Broker A), is both buying and selling the stock during the same day. We classify such a broker as an "intermediary" as he appears to be trading on behalf of a number of outside investors. The broker in column (2) however, (Broker B), only buys or sells the stock on a given day. This suggests that the broker is trading only on his own behalf or on behalf of a single party. Broker B is clearly not intermediating on behalf of many outside investors. For this reason we define broker B as a "principal". Whether a broker is a principal or not is captured by our "principalness" measure, PRIN, defined as the probability (over time) that a given broker in a given stock will behave as a principal. A broker on a given day is said to behave as a principal, if he either does a buy transaction only, or a sale transaction only, or buys and sells the same amount of a stock on a given day. Using this definition, the PRIN values calculated for brokers A and B are 0.05 and 1 respectively. 
Table 2: Types of Trades

\begin{tabular}{|c|c|c|c|c|c|}
\hline \multirow[b]{3}{*}{ Trade Type } & \multirow{3}{*}{$\begin{array}{c}\text { (1) } \\
\text { Frequency } \\
\text { Observed } \\
\end{array}$} & (2) & (3) & \multirow{3}{*}{$\begin{array}{c}\text { (4) } \\
\text { Normalized } \\
\text { Firm Price }\end{array}$} & \multirow{3}{*}{$\begin{array}{c}\text { (5) } \\
\text { Normalized } \\
\text { Turnover } \\
\end{array}$} \\
\hline & & \multicolumn{2}{|c|}{ Percentage by Volume } & & \\
\hline & & All but top 10 & Top 10 Firms & & \\
\hline Cycle & $21.2 \%$ & $19.6 \%$ & $3.7 \%$ & 100 & 116 \\
\hline Principal Buy & $20.1 \%$ & $7.4 \%$ & $1.9 \%$ & 98.3 & 76 \\
\hline Principal Sale & $17.4 \%$ & $7.7 \%$ & $2.0 \%$ & 100 & 85 \\
\hline Intermediary & $41.3 \%$ & $65.2 \%$ & $92.2 \%$ & 108.8 & 167 \\
\hline$N$ & 2.2 Million & 1.5 Million & 0.7 Million & 2.2 Million & 2.2 Million \\
\hline
\end{tabular}

Each observation is at the stock-broker-date level. A "trade" refers to the aggregate of all trades done by a broker during a single trading day for a given stock. A trade by a broker is defined as a "Cycle" if any one of these two conditions holds: (i) the trade is an only buy or an only sale, and it is exactly reversed the next time the broker trades. (ii) both buy and sale of the trade exactly equal each other out. For example, the trades in sequence 2 of broker B in Table 1 are all "cycle" trades. A trade by a broker is defined as a "Principal Buy" if he only buys in that trade (i.e. sale $=0$ ). The trades in sequence 1 of broker B in Table 1 are all Principal Buys. A trade by a broker is defined as a "Principal Sale" if he only sells in that trade (i.e. buy $=0$ ) i.e. trades in sequence 3 of broker B in Table 1 . A trade by a broker is defined as "Intermediary" if both sale and buy are positive (but not equal to each other). Almost all trades of broker A in Table 1 are intermediary trades. 
Table 3: Measuring Profitability of Principal Trades

\begin{tabular}{|c|c|c|c|c|c|c|c|c|}
\hline \multicolumn{9}{|c|}{ Panel A: Entire Period } \\
\hline & (1) & (2) & (3) & (4) & (5) & (6) & (7) & (8) \\
\hline & $\begin{array}{c}\mathbf{A R R} \\
\text { (unweighted) }\end{array}$ & ARR & ARR & $\begin{array}{c}\mathbf{A R R} \\
(40 \% \\
\text { margin })\end{array}$ & $\begin{array}{c}\mathbf{A R R} \\
(20 \% \\
\text { margin })\end{array}$ & ARR & ARR & $\begin{array}{c}\text { ARR } \\
\text { (top 10\% } \\
\text { stocks } \\
\text { only) }\end{array}$ \\
\hline PRIN & $\begin{array}{c}34.65 \\
(11.05)\end{array}$ & $\begin{array}{c}48.44 \\
(11.55)\end{array}$ & $\begin{array}{c}48.42 \\
(11.62)\end{array}$ & $\begin{array}{c}71.71 \\
(28.75)\end{array}$ & $\begin{array}{c}88.80 \\
(32.46)\end{array}$ & & $\begin{array}{c}34.39 \\
(19.15)\end{array}$ & $\begin{array}{c}48.57 \\
(11.60)\end{array}$ \\
\hline$P R I N=1 ?$ & & & $\begin{array}{c}0.29 \\
(2.22)\end{array}$ & & & & & \\
\hline PRIN ${ }^{\text {ord }}$-decile & & & & & & $\begin{array}{l}26.8 \\
(5.6)\end{array}$ & & \\
\hline PRIN*KSE100? & & & & & & & $\begin{array}{c}14.46 \\
(22.56)\end{array}$ & \\
\hline $\begin{array}{l}N \\
R-s q\end{array}$ & $\begin{array}{c}46325 \\
0.11\end{array}$ & $\begin{array}{c}46325 \\
0.10\end{array}$ & $\begin{array}{c}46325 \\
0.10\end{array}$ & $\begin{array}{c}46325 \\
0.06\end{array}$ & $\begin{array}{c}46324 \\
0.05\end{array}$ & $\begin{array}{c}46325 \\
0.09\end{array}$ & $\begin{array}{c}46325 \\
0.08\end{array}$ & $\begin{array}{l}9458 \\
0.09\end{array}$ \\
\hline \multicolumn{9}{|c|}{ Panel B: Three sub-periods (Dependent Variable $=$ ARR) } \\
\hline & & (9) & & (10) & & (11) & & \\
\hline & & $\begin{array}{c}\text { Dec } 98 \\
\text { to Oct } 99\end{array}$ & & $\begin{array}{l}\text { Nov } 99 \\
\text { to Sep } 00\end{array}$ & & $\begin{array}{l}\text { Oct } 00 \text { to } \\
\text { Aug } 01\end{array}$ & & \\
\hline Market Volatility & & 15.0 & & 10.8 & & 9.5 & & \\
\hline PRIN & & $\begin{array}{c}114.64 \\
(32.2)\end{array}$ & & $\begin{array}{c}53.6 \\
(39.2)\end{array}$ & & $\begin{array}{l}179.0 \\
(75.2)\end{array}$ & & \\
\hline$N$ & & 21,334 & & 36,681 & & 30,837 & & \\
\hline$R-s q$ & & 0.02 & & 0.01 & & 0.01 & & \\
\hline
\end{tabular}

Robust standard errors in parentheses

All regressions weighted (except 1) and include firm fixed effects

Each observation is at the stock-broker level. ARR is the annualized rate of return on stock-broker's trades. PRIN is a measure of the "principalness" of a stock-broker, as explained in Table 1. In Panel B Market Volatility is the standard deviation of monthly market return during the sub-sample. Also note that the number of observations in Panel B may be different from that in Panel A since not all brokers (or even stocks) are active throughout the three sub-periods. 
Table 4: State Contingent Returns

\begin{tabular}{|c|c|c|c|c|}
\hline & \multicolumn{4}{|c|}{ Weekly Excess Return using Strategy: } \\
\hline & $\boldsymbol{H H}$ & $L L$ & HHend & LLend \\
\hline & \multicolumn{4}{|c|}{ Panel A: High/Low Cutoff at Firm's Median PRIN } \\
\hline & $(1)$ & (2) & (3) & (4) \\
\hline Constant & $\begin{array}{c}0.12 \\
(0.08)\end{array}$ & $\begin{array}{c}-0.20 \\
(0.076)\end{array}$ & $\begin{array}{c}0.56 \\
(0.15)\end{array}$ & $\begin{array}{l}-0.64 \\
(0.15)\end{array}$ \\
\hline \multirow[t]{3}{*}{$N$} & 141 & 141 & 141 & 141 \\
\hline & \multicolumn{4}{|c|}{ Panel B: Top two deciles stocks only } \\
\hline & (5) & (6) & (7) & (8) \\
\hline Constant & $\begin{array}{c}0.04 \\
(0.11)\end{array}$ & $\begin{array}{l}-0.08 \\
(0.07)\end{array}$ & $\begin{array}{c}0.24 \\
(0.15)\end{array}$ & $\begin{array}{l}-0.68 \\
(0.16)\end{array}$ \\
\hline$N$ & 141 & 141 & 141 & 141 \\
\hline
\end{tabular}

Robust standard errors in parentheses

Columns (1) through (4) regress the 141 weekly excess or "above-market" returns from using different strategies. A strategy X refers to holding each week a portfolio that contains all the stocks which had a state X the previous week. A stock is in $H H$ state in a given week if the average PRIN of both buyers and sellers of the stock that week is high (in other words mostly the principals are trading amongst themselves that week). A stock is in $L L$ state in a given week if the average PRIN of both buyers and sellers of the stock that week is low (in other words mostly the intermediaries trading amongst themselves that week). HHend and LLend have similar definitions to $H H$ and $L L$, differing only in that the state next week must not be $H H$ and $L L$ respectively. 
Table 5: Testing Alternate Theories

\begin{tabular}{|c|c|c|c|c|c|}
\hline & $\begin{array}{c}\mathbf{( 1 )} \\
\text { ARR } \\
\text { Broker FEs }\end{array}$ & $\begin{array}{c}(2) \\
\text { ARR }\end{array}$ & $\begin{array}{c}(3) \\
\text { ARR }\end{array}$ & $\begin{array}{c}(4) \\
\text { ARR }\end{array}$ & $\begin{array}{c}(5) \\
\text { ARR }\end{array}$ \\
\hline PRIN & $\begin{array}{l}37.33 \\
(12.45)\end{array}$ & & $\begin{array}{l}46.94 \\
(11.67)\end{array}$ & $\begin{array}{l}48.30 \\
(11.57)\end{array}$ & \\
\hline $\begin{array}{l}\text { 3-cycle component of } \\
\text { PRIN }\end{array}$ & & $\begin{array}{l}30.67 \\
(12.73)\end{array}$ & & & \\
\hline $\begin{array}{l}\text { Non 3-cycle component of } \\
\text { PRIN }\end{array}$ & & $\begin{array}{l}50.94 \\
(12.17)\end{array}$ & & & \\
\hline $\begin{array}{l}\text { Share of stock vol. traded } \\
\text { by the broker }\end{array}$ & & & $\begin{array}{l}-52.02 \\
(41.15)\end{array}$ & & \\
\hline $\begin{array}{l}\text { Avg. normalized turnover } \\
\text { on days the broker trades }\end{array}$ & & & & $\begin{array}{l}0.37 \\
(0.46)\end{array}$ & \\
\hline Cycle component of PRIN & & & & & $\begin{array}{l}35.96 \\
(12.57)\end{array}$ \\
\hline $\begin{array}{l}\text { Non-cycle component of } \\
\text { PRIN }\end{array}$ & & & & & $\begin{array}{l}54.82 \\
(12.48)\end{array}$ \\
\hline$N$ & 46325 & 46325 & 46325 & 46325 & 46325 \\
\hline$R-s q$ & 0.20 & 0.10 & 0.10 & 0.10 & 0.10 \\
\hline
\end{tabular}

Robust standard errors in parentheses

All regressions weighted and include firm fixed effects

Column (1) also includes broker fixed effects

Each observation is at the stock-broker level. ARR is the annualized rate of return on stock-broker's trades. PRIN is a measure of the "principalness" of a stock-broker, as explained it Table 1. 3-cycles are a subset of the "cycles" described in Table 1, with the added condition that such cycles should be observed consecutively and for at least three times. 


\section{Table A1: Profitability Calculation Example}

\begin{tabular}{|c|c|c|c|c|c|c|c|c|c|c|}
\hline & (1) & (2) & (3) & (4) & $(5)$ & (6) & (7) & (8) & (9) & (10) \\
\hline \multirow[b]{2}{*}{ Date } & & AW DATA & & $(2)-(1)$ & $\begin{array}{c}\text { Running } \\
\text { Sum of (4) }\end{array}$ & $\begin{array}{l}(3) *-(4): \\
\text { if }(4)<0\end{array}$ & $\begin{array}{l}(3) *(4): \text { if } \\
(4)>0\end{array}$ & $|(5)|^{*}(3)$ & & \\
\hline & $\begin{array}{r}\text { Shares } \\
\text { Sold }\end{array}$ & $\begin{array}{l}\text { Shares } \\
\text { Bought }\end{array}$ & $\begin{array}{l}\text { Stock } \\
\text { Price }\end{array}$ & $\begin{array}{r}\text { Net } \\
\text { Shares } \\
\text { Bought }\end{array}$ & $\begin{array}{r}\text { Share } \\
\text { "Inventory" }\end{array}$ & "Rеvеnue" & "Investment" & $\begin{array}{r}\text { Gross } \\
\text { Capital } \\
\text { Required }\end{array}$ & $\begin{array}{r}\text { Net } \\
\text { Running } \\
\text { Profit }\end{array}$ & $\begin{array}{r}\text { Net Capital } \\
\text { Required }\end{array}$ \\
\hline 1 & 143,000 & 139,000 & 1 & $-4,000$ & $-4,000$ & 4,000 & - & 4,000 & 4,000 & - \\
\hline 2 & 151,000 & 120,500 & 1 & $-30,500$ & $-34,500$ & 30,500 & - & 34,500 & 34,500 & - \\
\hline 3 & 49,500 & 78,500 & 1 & 29,000 & $-5,500$ & - & 29,000 & 5,500 & 5,500 & - \\
\hline 4 & 0 & 42,500 & 1 & 42,500 & 37,000 & - & 42,500 & 37,000 & $(37,000)$ & 74,000 \\
\hline 5 & 65,000 & 214,000 & 1 & 149,000 & 186,000 & - & 149,000 & 186,000 & $(186,000)$ & 372,000 \\
\hline 6 & 77,000 & 256,000 & 2 & 179,000 & 365,000 & - & 358,000 & 730,000 & $(544,000)$ & $1,274,000$ \\
\hline 7 & 408,500 & 43,500 & 2 & $-365,000$ & 0 & 730,000 & - & - & 186,000 & - \\
\hline 8 & 2,000 & 24,000 & 2 & 22,000 & 22,000 & - & 44,000 & 44,000 & 142,000 & - \\
\hline 9 & 2,500 & 10,000 & 2 & 7,500 & 29,500 & - & 15,000 & 59,000 & 127,000 & - \\
\hline 10 & 0 & 69,000 & 2 & 69,000 & 98,500 & - & 138,000 & 197,000 & $(11,000)$ & 208,000 \\
\hline \multicolumn{2}{|c|}{$\begin{array}{l}\text { End of Period } \\
\text { Liquidation }\end{array}$} & & 2 & $-98,500$ & 0 & 197,000 & - & - & 186,000 & - \\
\hline
\end{tabular}

$A R R=$ the annualized nominal rate of return based on the brokers total net profit (186,000 above) for a given average capital investment (192,800 above). Thus using this example the rate of return for the trades shows would be $96 \%$. ARR would then be the annualized equivalent of this rate of return. 